\title{
The Herd Health Handbook for Goat Producers: Biosecurity at the Farm Level ${ }^{1}$
}

Ray Mobley and Carmen Lyttle-N'guessan ${ }^{2}$

\section{Introduction}

Bio-security (biological safety and well-being) is the management practices that prevent infectious diseases from being carried into a herd. The goal of a bio-security program is to stop the transmission of disease-causing agents by preventing, minimizing or controlling cross-contamination of body fluids between animals, animals to feed, or equipment that may directly or indirectly contact animals. Effective biosecurity management practices are designed to prevent the spread of disease by minimizing movement of biological organisms and their vectors onto and within the premises. These management practices are based on the principle that it is easier to prevent disease than it is to treat or react to a problem caused by disease.

The advantages of adopting a bio-security program are numerous. An effective program can improve the cost-efficiency of the farm, improve the reputation of the producer, and allow the producer to better maintain the health status of the herd. A bio-security program is one of the most effective means of disease control available, and no disease prevention program will work without it.

\section{Disease: Its Causes and How it is Spread}

One of the first steps that must be taken to implement a bio-security program is to learn what causes disease and illness so that it can be prevented. Diseases and ill health are the result of bacteria that cause caseous lymphanitis, viruses as in the case of CAE (caprine arthritis encephalatis) and pinkeye, or by parasites such as coccidia and Haemonchus. The spread of disease is multifactorial. It depends on the immune state or condition of the animal, the environment temperature, equipment, stocking rate, condition of the pasture, etc., and the sources of transmission. The key to a good bio-security program is to break the transmission of disease or minimize its effect. Issues that must be considered in the spread or transmission of diseases in a goat herd are:

1. The introduction of diseased goats or healthy goats incubating the diseases, also known as carrier animals;

2. The possibility of contamination by vehicles, equipment, clothing, etc;

3. Contact with contaminated inanimate objects;

4. Proper and timely disposal of carcasses of dead animals;

5. Proper management of feedstuffs and water to ensure that they do not become contaminated;

6. The proper handling of manure; and

7. The control of non-livestock vectors (other animals that can carry and spread the disease such as insects and arthropods).

\section{Aspects of an Effective Bio-security Program}

The issues that an effective biosecurity program must address can be quite complicated and diverse as seen in the diagram below (Figure 1). This is because of the many routes through which diseases can be spread. Although the issues that a bio-security program must address are diverse and complicated, the management practices that are a part of an effective program are usually simple and easy to incorporate into a normal production system.

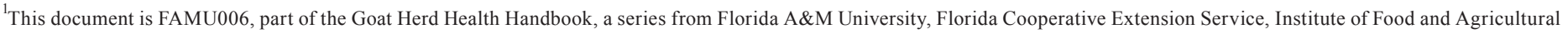
Sciences, University of Florida. Original publication date September 2009. Visit the EDIS Web Site at http://edis.ifas.ufl.edu.

${ }^{2}$ Ray Mobley, director, Cooperative Extension; Carmen Lyttle-N'guessan, veterinary care manager; Florida A\&M University, College of Engineering Sciences, Technology and Agriculture, Cooperative Extension Programs; Florida Cooperative Extension Service, Institute of Food and Agricultural Sciences, University of Florida, Gainesville, FL 32611.

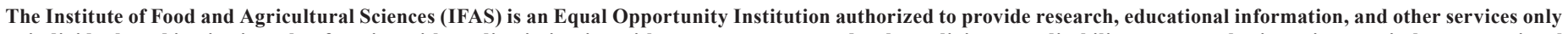

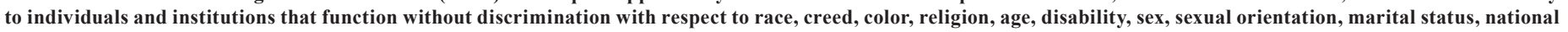

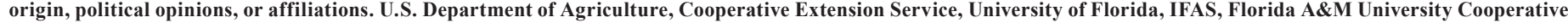
Extension Program, and Boards of County Commissioners Cooperating. Millie Ferrer-Chancy, Interim Director 
One of the first and most important aspects of a bio-security program that should be incorporated into the management plan of a producer is to know what is normal and abnormal both in the live animal and at slaughter. This requires that the owners and the inspectors are on the same page. The following diagram is an example of conditions or signs that an inspector looks for in order to decide if there is indeed a health problem. This is also a good list of symptoms for a producer to look for in order to be able to know the health status of his or her herd or individual animals.

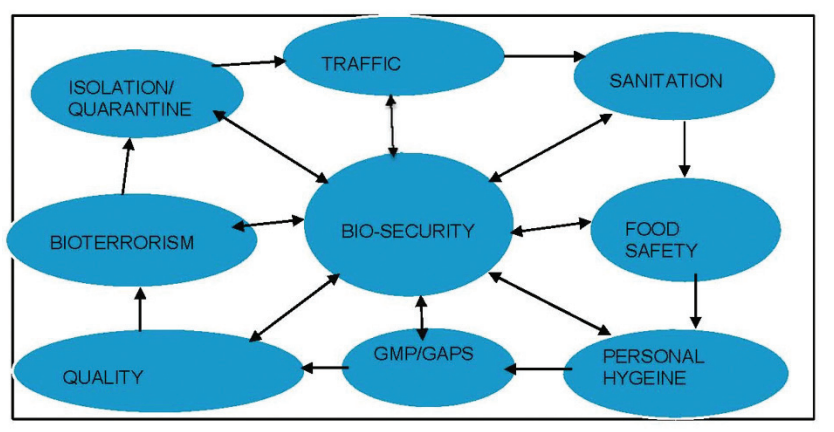

Figure 1: Diagram of a Biosecurity Program

Key:

GMP: Good Manufacturing Practices

GAPs Good Agricultural Practices

Impact-Dependent

Figure 1. Diagram of a Bio-security Program

Table 1. Health Alerts

\begin{tabular}{|l|l|}
\hline Healthy Goats & \multicolumn{1}{|c|}{ Signs of IIIness } \\
\hline Good appetite & Poor appetite \\
\hline Shiny coat & $\begin{array}{l}\text { Dull coat, hair falling } \\
\text { out }\end{array}$ \\
\hline Bright and clear eyes & Runny eyes \\
\hline Well fleshed & Weight loss \\
\hline $\begin{array}{l}\text { Normal body tempera- } \\
\text { ture } 103.1 \text { - } 104.9^{\circ} \mathrm{F}\end{array}$ & $\begin{array}{l}\text { Fever } 105.8^{\circ} \mathrm{F} \text { or } \\
\text { higher }\end{array}$ \\
\hline Strong legs and feet & $\begin{array}{l}\text { Lameness, swollen } \\
\text { joints }\end{array}$ \\
\hline Pink gums & Anemic (pale gums) \\
\hline Firm pelleted stool & Diarrhea \\
\hline $\begin{array}{l}\text { No swelling in any ex- } \\
\text { tremities of the body }\end{array}$ & $\begin{array}{l}\text { Swelling in any body } \\
\text { parts }\end{array}$ \\
\hline Chewing its cud & $\begin{array}{l}\text { No sign of chewing } \\
\text { cud }\end{array}$ \\
\hline Alert & Lethargic \\
\hline Breathing normal & Labored breathing \\
\hline $\begin{array}{l}\text { Urinates with no dif- } \\
\text { ficulty }\end{array}$ & $\begin{array}{l}\text { Strains or cries when } \\
\text { urinating }\end{array}$ \\
\hline
\end{tabular}

\section{Bio-security Measures}

1. The following are some measures and practices that should be adopted by the producer to ensure the safety and health of his or her herd:

2. It is best to prevent problems rather than correct them.

3. It is important that an individual and premises animal identification program is implemented.

4. Keep good records. It is suggested that the records be kept simple. The records should track and validate the different management practices conducted on the farm including the results of routine evaluations performed on the herd (Appendix B).

\section{Other bio-security measures that can be adopted into an effective program} are:

1. Attempt to prevent manure contamination by never stepping in the feed bunks.

2. Routinely clean and disinfect feeding and watering equipment, which can be done with chlorine, iodine or Quatenary Ammonia Products (QAPs).

3. Routinely clean and disinfect equipment used to medicate animals, especially equipment used on multiple animals.

4. Provide clean area for restraint, treatment and isolation of sick animals.

5. Consult with a veterinarian or animal health personnel on goats with suspicious symptoms or death.

6. Monitor and manage visitor traffic.

7. Clean contaminated vehicles and equipment.

8. Know health history of herd where new animals are purchased.

9. Know health status of animals brought into herd.

10. Transport animals in clean vehicle.

11. Quarantine and isolate new and sick animals.

12. Sanitarily dispose of dead stock.

13. Have a control program for other animals which could spread disease (rodents, insects, external parasites, etc.)

14. Control manure and dispose of it frequently. 
15. Maintain good personal hygiene.

16. Be observant.

17. Maintain a good client-patient relationship with a veterinarian.

18. Have a sound vaccination program.

\section{Food Safety Concerns}

As food safety is of a great concern to consumers, it is important that the producer plays his or her part in ensuring that food supply is safe. This can be done by conducting an antemortem inspection of animals before they are sold or slaughtered for human consumption. The inspection should determine if there are signs of physical, biological, or mental problems. This is done by looking at the movement of the animal in addition to the skin, eyes, nose, external reproductive system, mouth and feet. The person that is inspecting the animal is looking for conditions such as caseous lymphadenitis, epithelioma, anasarca, comatose, signs that the animal is dying, animals that are not walking normally or will not stand, missing eyes, bloating, the swelling of joints or briskets, respiratory problems, swollen lymph nodes, lumpy jaws, or signs of central nervous system problems. Some diseases that should be monitored include anthrax, rabies, tetanus, foot and mouth disease, scrapies, brucellosis, and goat and sheep pox (Appendix A).

The producer should know a little about the postmortem inspection. It is usually done simultaneously with the slaughter and dressing process. It is divided into three sections: the head, the viscera, and the rail inspection. The inspector examines and palpates the external surface of the heart. The lymph nodes of the lungs are palpated. The inspector also examines the liver, the bile duct, the spleen, paunch and the intestine. Then, the surface of the carcass, the thorax, abdominal, pelvic cavity, and the kidneys are examined. He will also look for fecal material.

If it is determined that the carcass has the following conditions, it will be condemned and not allowed to enter the system for human consumption:

1. Anthrax

2. Rabies

3. Extreme emaciation

4. Pneumonia

5. Uremic poisoning

6. Tuberculosis

7. Icterus

8. Septicemia
9. Caseous lymphadenitis

10. Abscesses

11. Fecal material

\section{How does HACCP Work?}

HACCP (Hazard Analysis and Critical Control Point) allows the producer to converse with his customers using the same food safety blueprint they are required to use. HACCP works at the producer level as it does for customers receiving on-farm products. It requires the producer to conduct a hazard analysis to determine what significant hazards can occur at the farm level. This must be done in order to plan for and execute a program that will prevent or control their occurrence.

The framework of a HACCP-based food safety program is possible at the producer level. Although it will require modifications, its implementation can enhance a farm-to-table approach to food safety and increase the confidence of customers purchasing producer products. This system can also make the management of herd health and other concerns much more user-friendly. Producers are expected to know the role they play in combating food-borne illnesses. Using a sound science-based program will enhance the total food safety approach and give increased credibility to on-farm management programs.

\section{The basic principles of HACCP are:}

1. To conduct hazard analysis

2. To establish critical control points

3. To establish critical limits

4. To establish monitoring procedures

5. To establish corrective actions

6. To establish verification procedures

7. To establish record-keeping and documentation procedures

\section{Conclusion}

Bio-security is very important to the entire agricultural industry from the producer to the consumer. The producer that can successfully control the introduction and spread of disease on their farm not only benefits himself but the entire industry. The control of disease cuts down on the cost of medication and treatment for the producer and increases the confidence of the consumer in the safety and wholesomeness of the products that are produced by the industry. A good bio-security program is essential to this success. 
Although a good biosecurity program must address many issues, it can still be simple and effective at the same time. The implementation of a program that focuses on prevention of disease includes an individual and premises identification program; tracks and validates management practices; keeps the environment sanitary; prevents cross-contamination between clean, healthy, sick and dead goats; and includes routine evaluations that should effectively control the spread and introduction of disease.

\section{References:}

Merck \& Company, Inc. (2008). Biosecurity: Goats. The Merck Veterinary Manual, http://www. merckvetmanual.com/mvm/index.jsp, Received July 22, 2009.

http://www.jackmauldin.com/diseases.htm. Received August 12, 2009.

Pugh, D. G. (2002). Sheep and goat medicine, 1st ed. pp. 210-211 \& 397-398. Saunders, Philadelphia.

Steveson, K. E., \& Bernard, D. T. (1995). Establishing hazard analysis critical control point program: A workshop manual 2nd ed. The food processors institute 1350 I Street, N.W., Suite 300 Washington, D. C. 20005-3305. 


\begin{tabular}{|c|c|c|}
\hline & 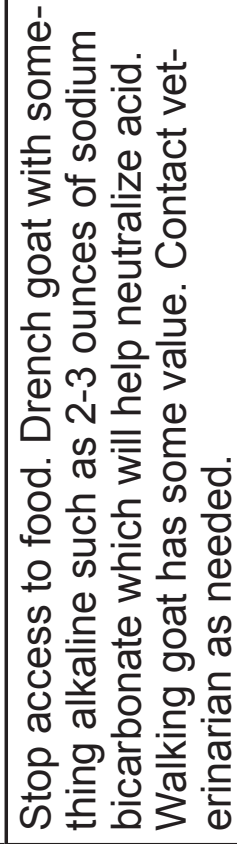 & 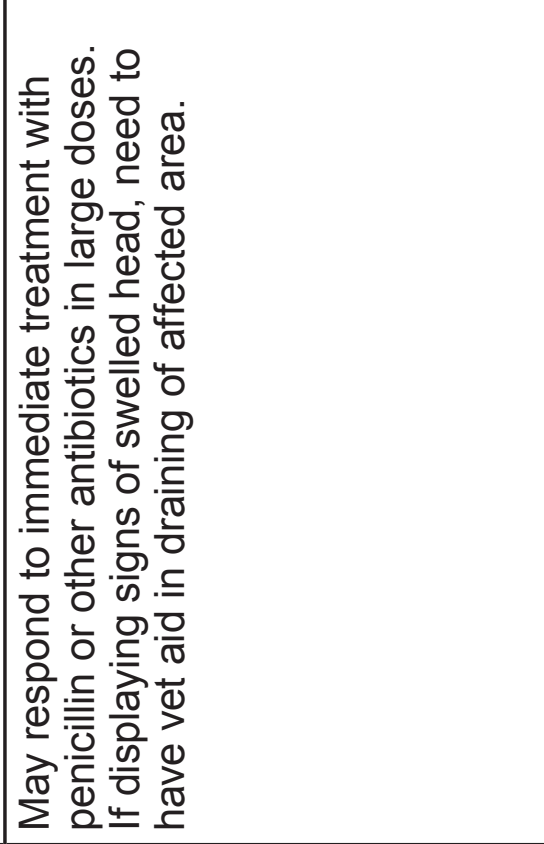 \\
\hline 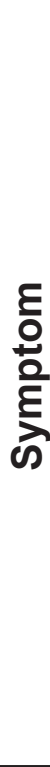 & 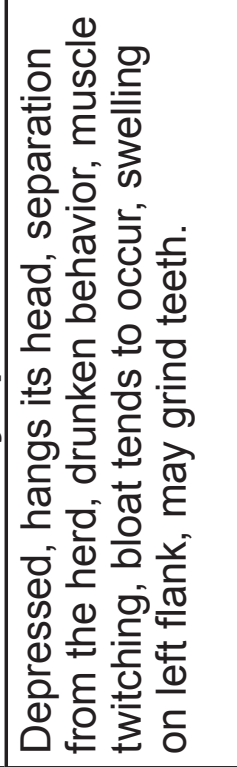 & 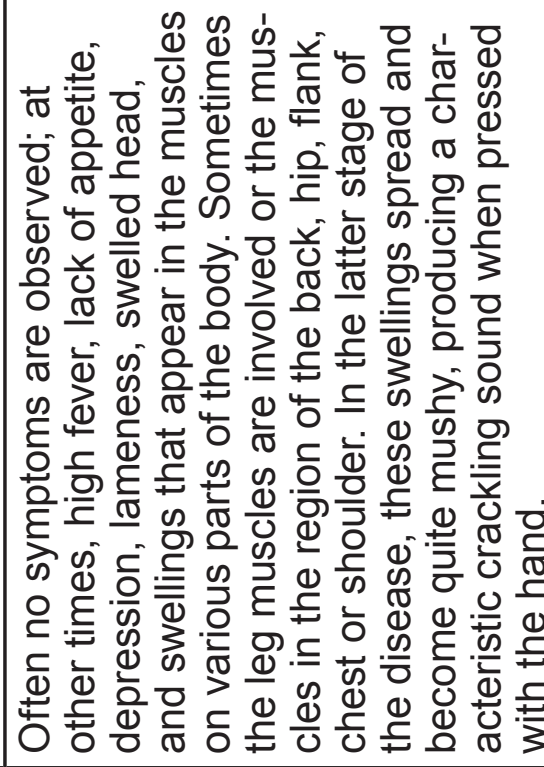 \\
\hline 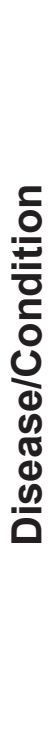 & 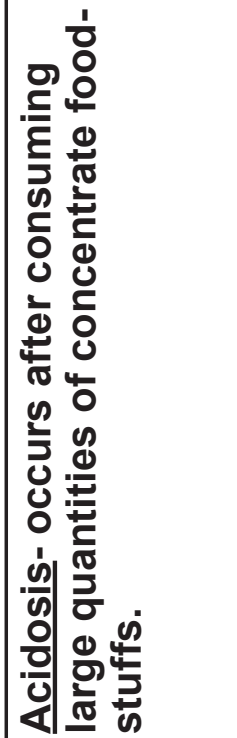 & 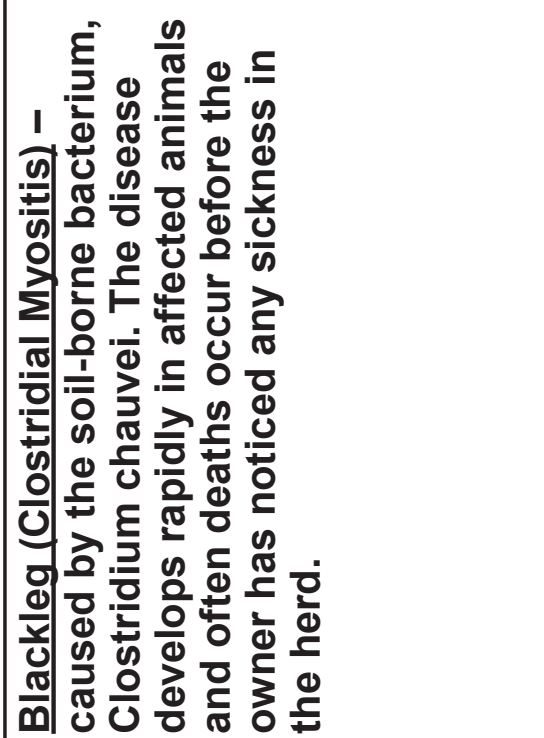 \\
\hline
\end{tabular}




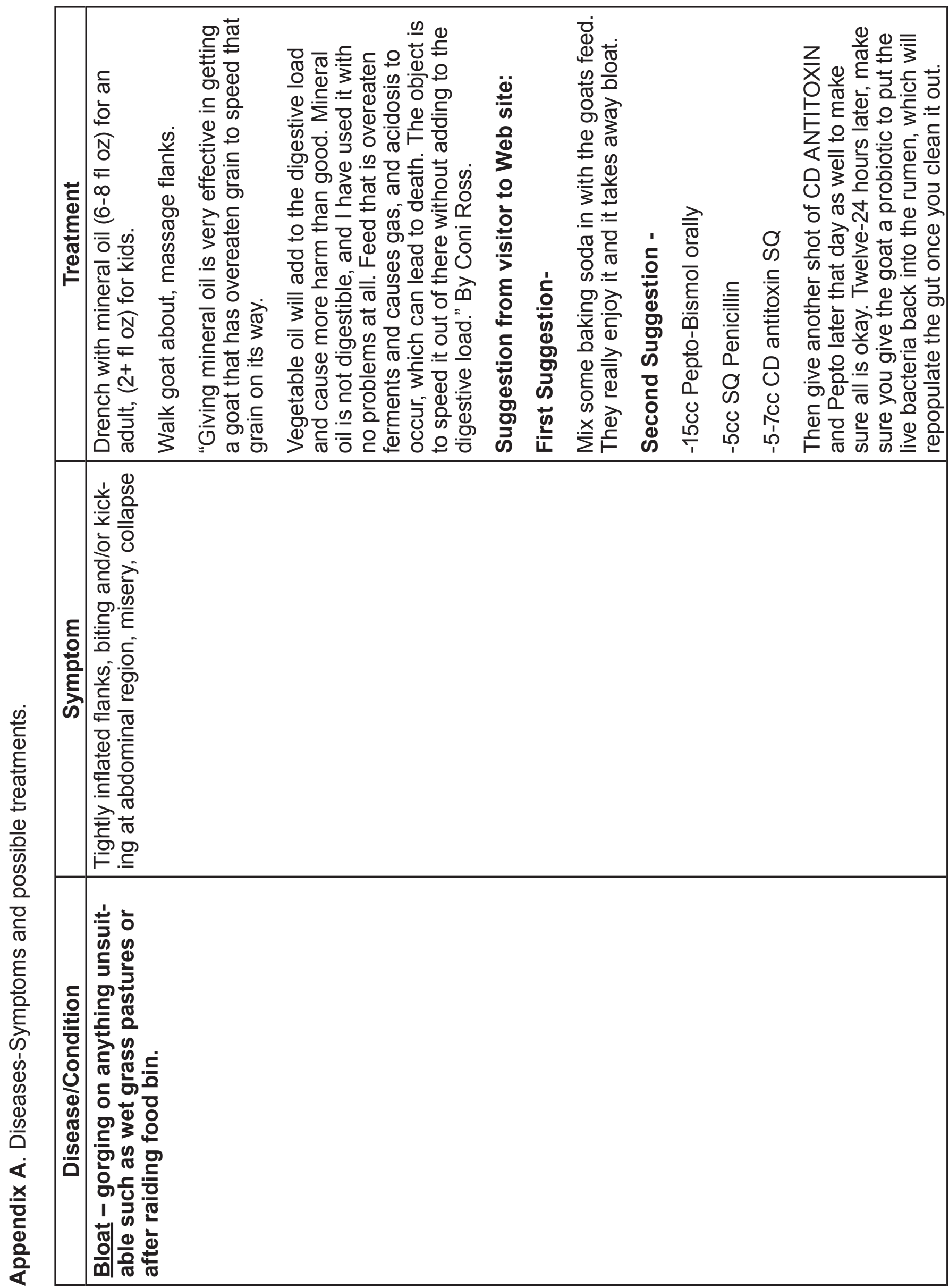




\begin{tabular}{|c|c|c|c|c|c|}
\hline & 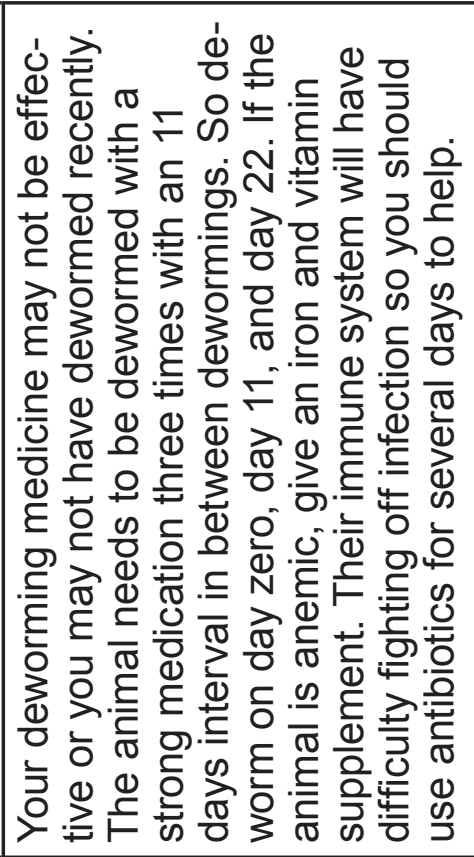 & 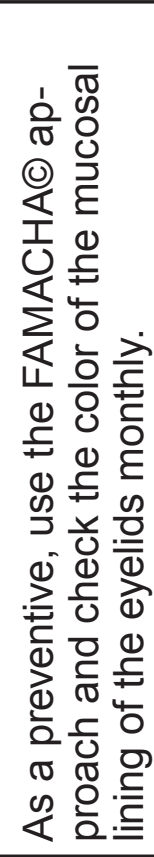 & 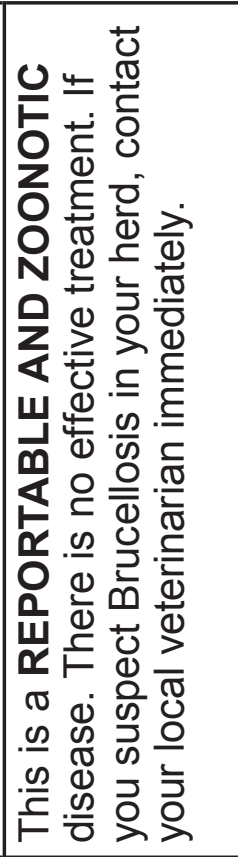 & 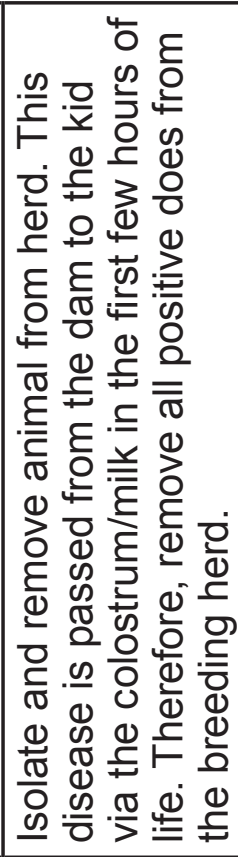 & 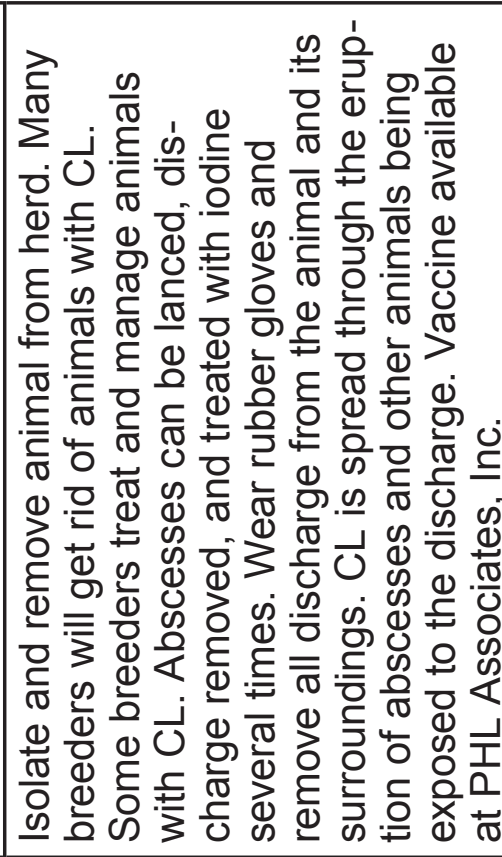 \\
\hline $\begin{array}{l}\frac{\varepsilon}{\rho} \\
\frac{+}{2} \\
\frac{\text { 을 }}{\lambda}\end{array}$ & 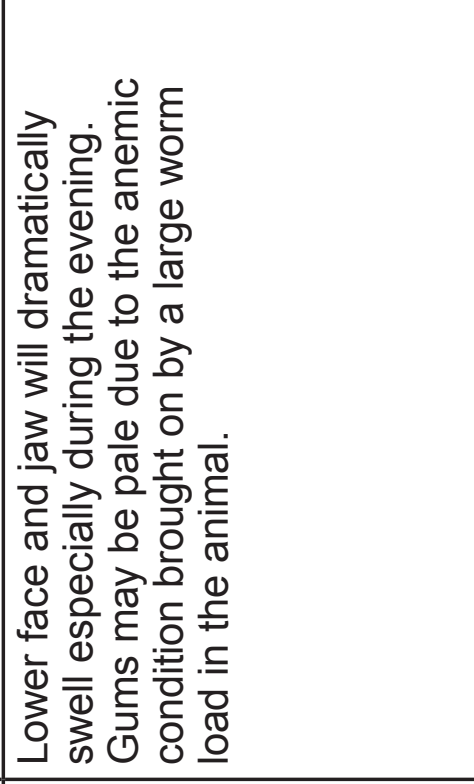 & & 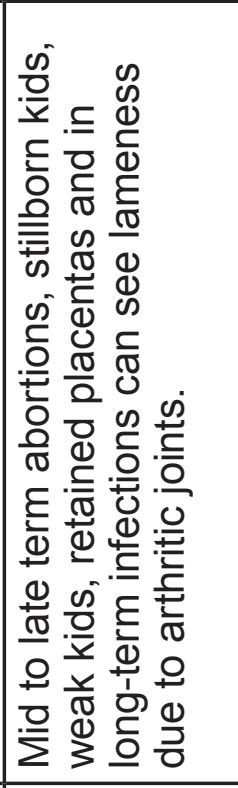 & 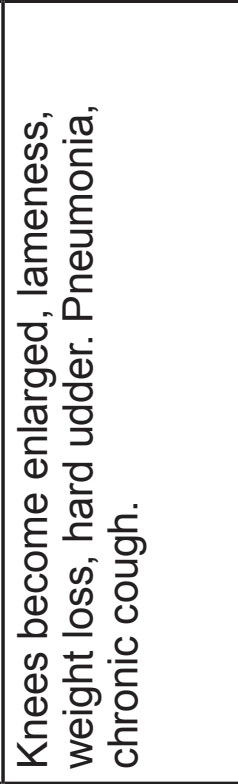 & 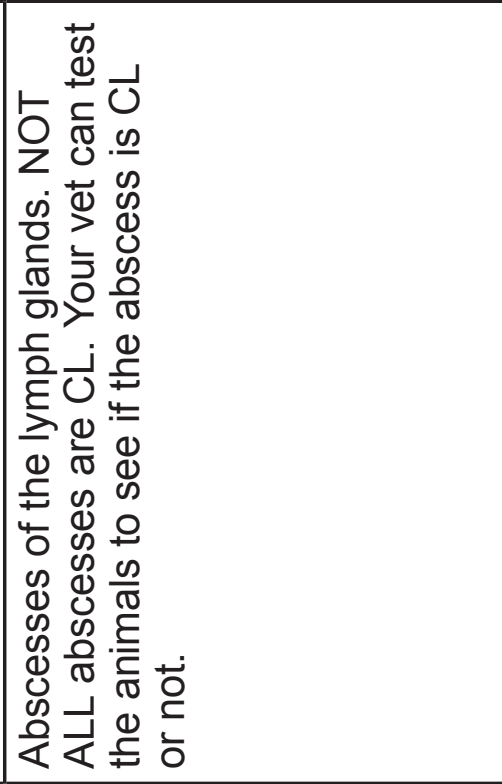 \\
\hline 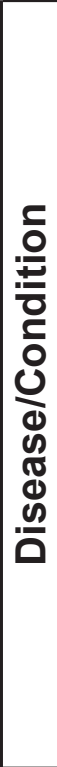 & 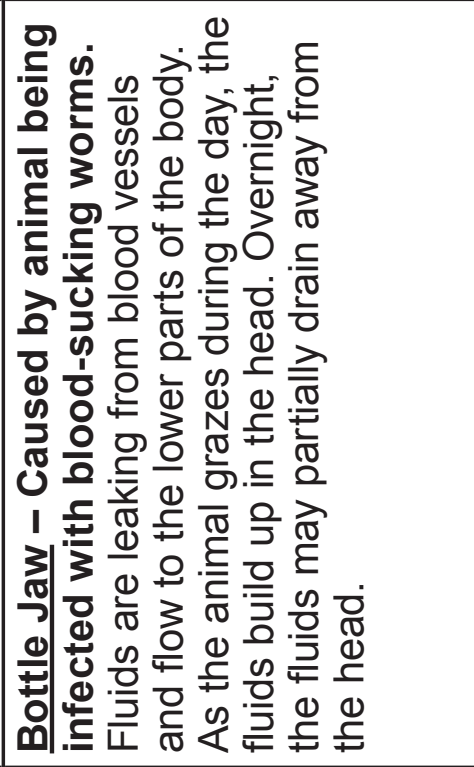 & & 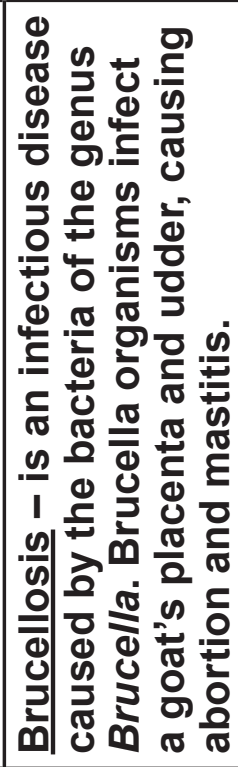 & 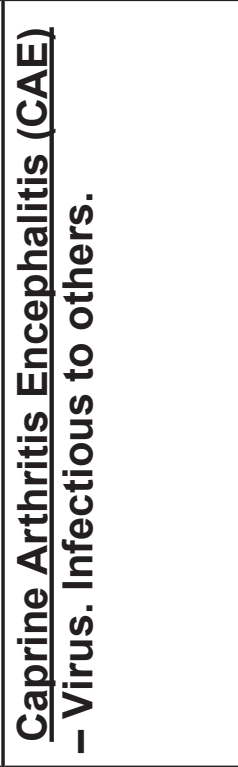 & 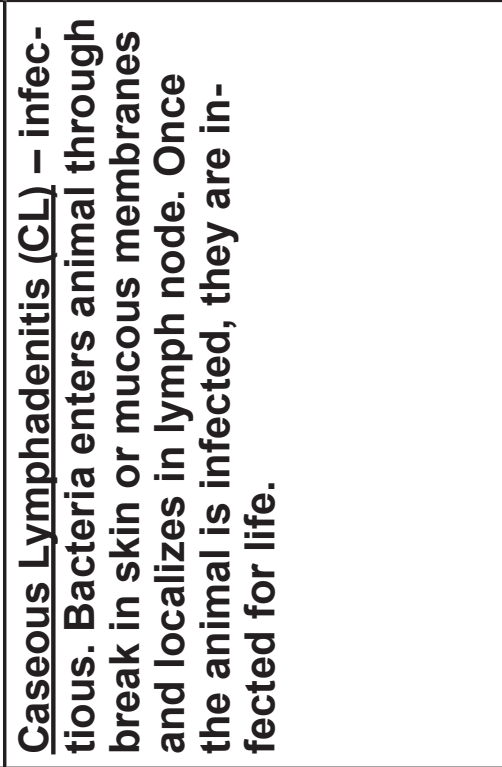 \\
\hline
\end{tabular}




\begin{tabular}{|c|c|c|c|c|c|c|}
\hline & 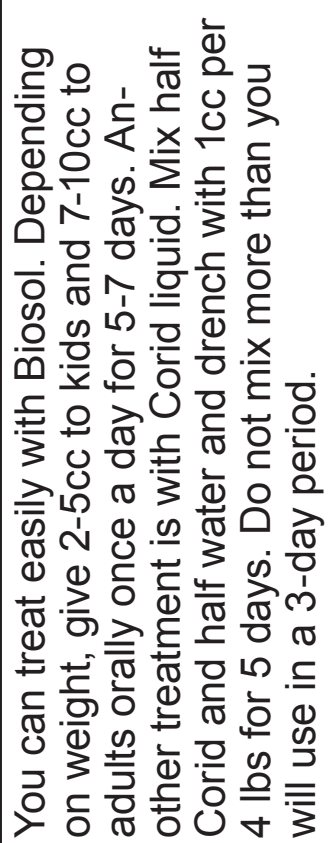 & 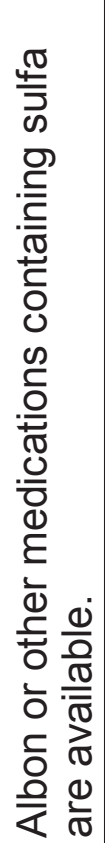 & 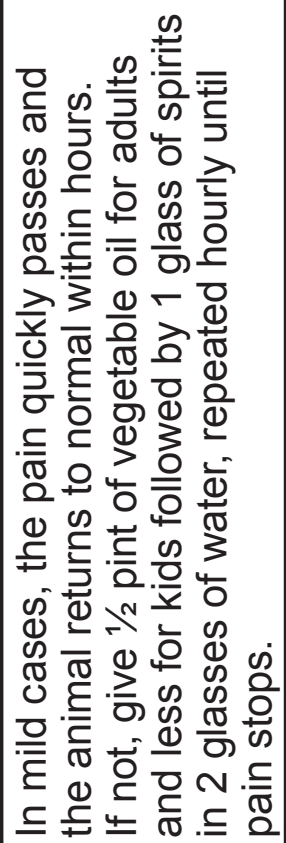 & 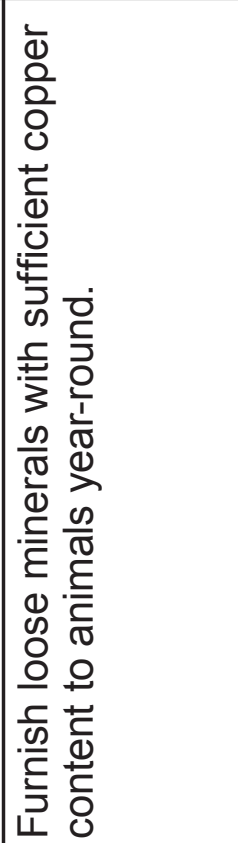 & 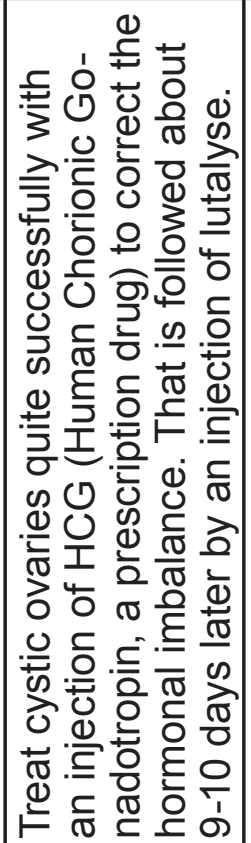 & 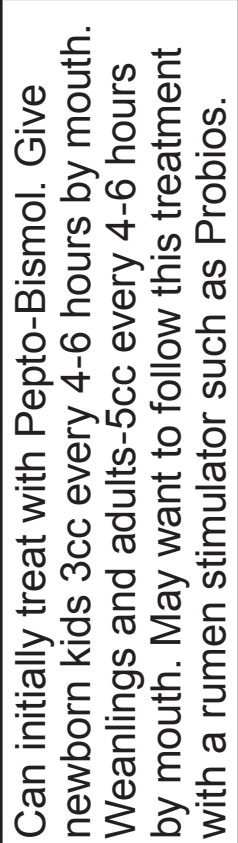 \\
\hline 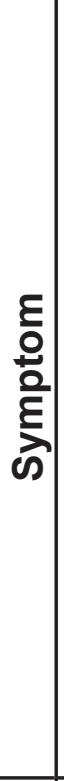 & 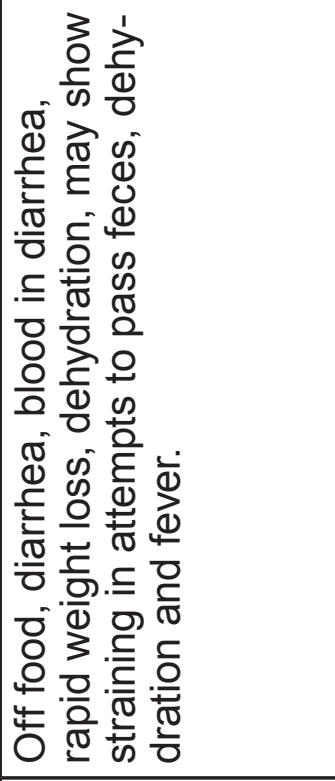 & & 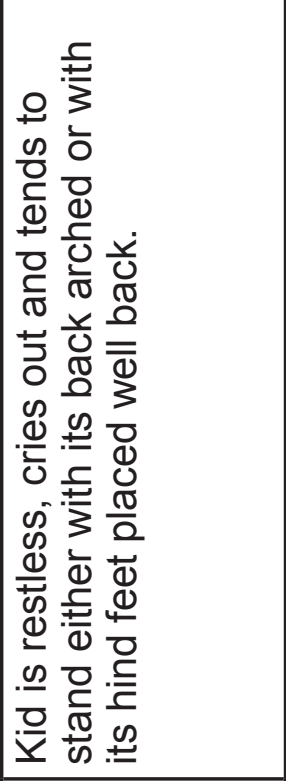 & 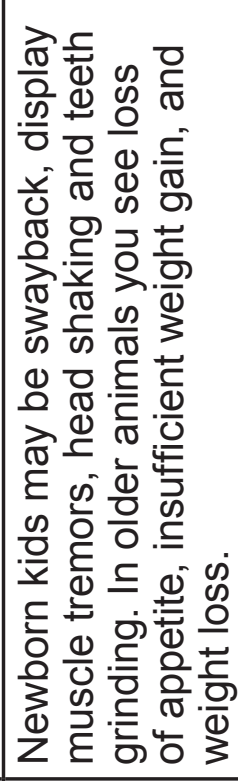 & 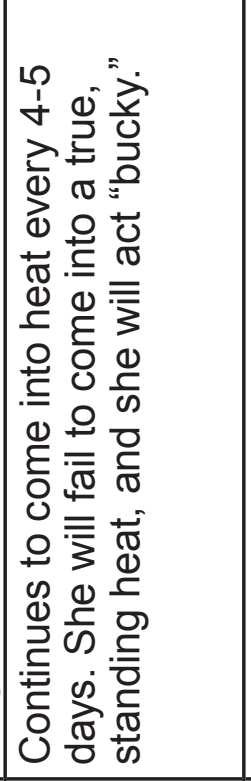 & 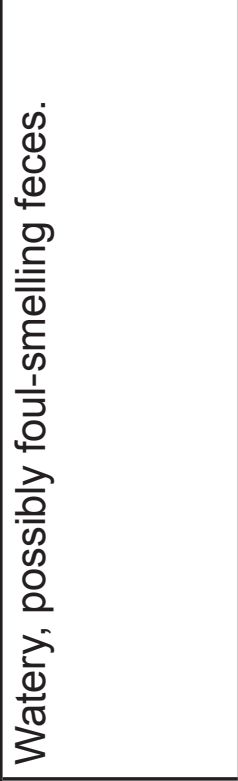 \\
\hline 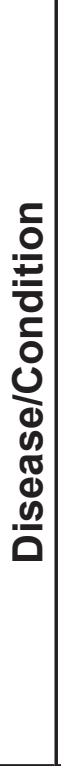 & 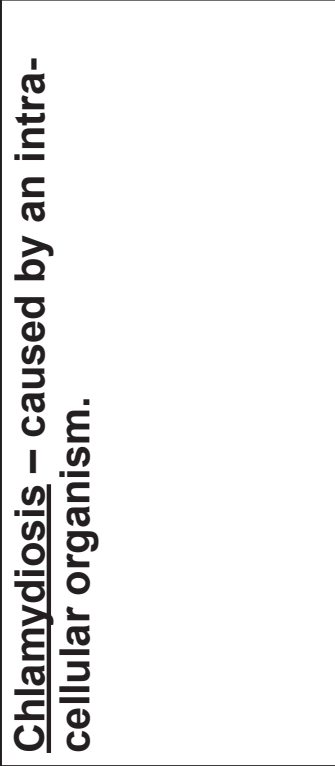 & & 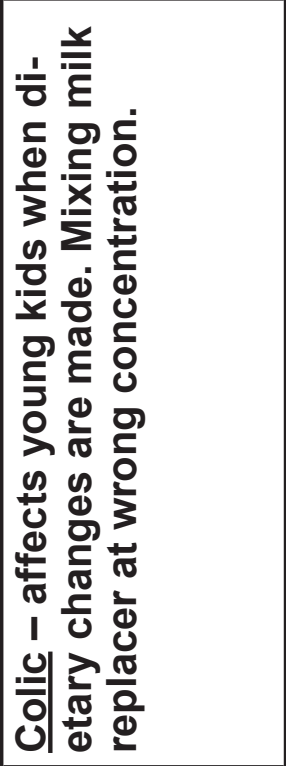 & 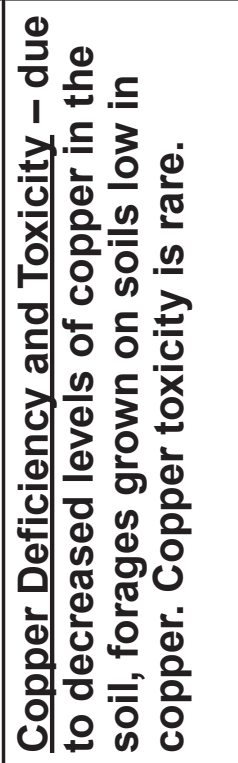 & 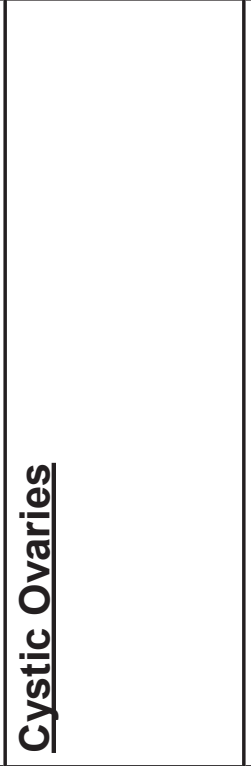 & 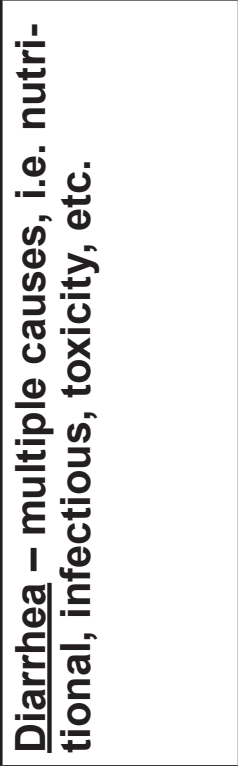 \\
\hline
\end{tabular}




\begin{tabular}{|c|c|c|c|c|c|}
\hline & 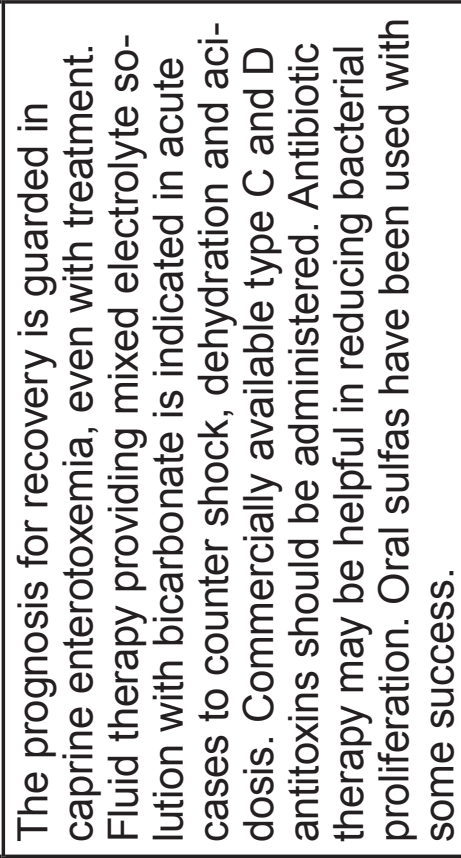 & 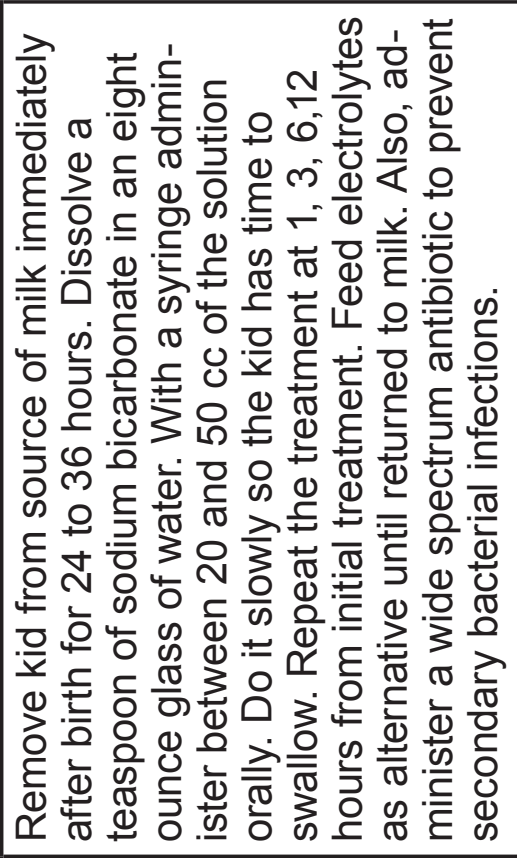 & 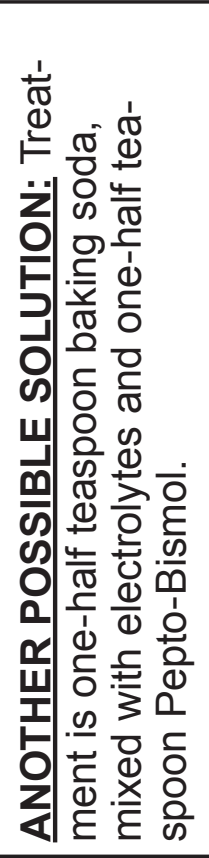 & 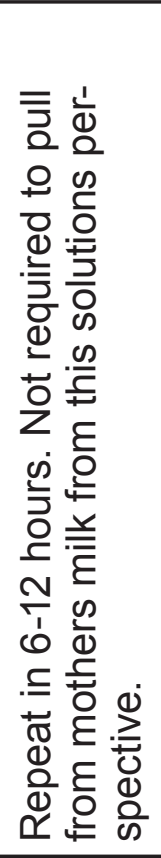 & 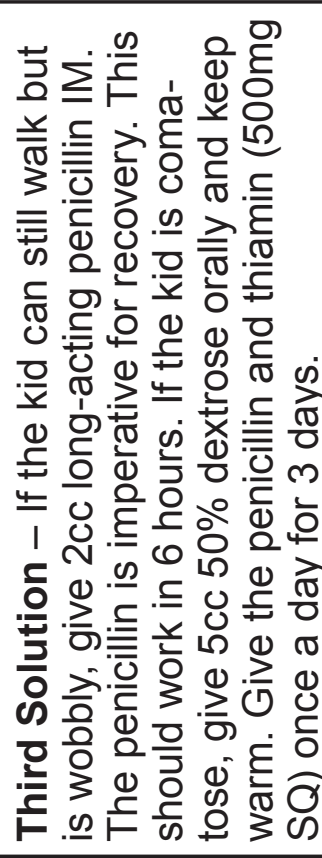 \\
\hline & 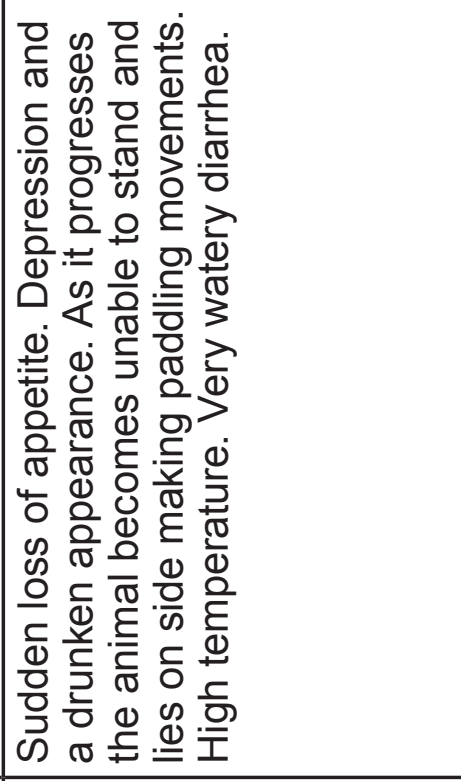 & 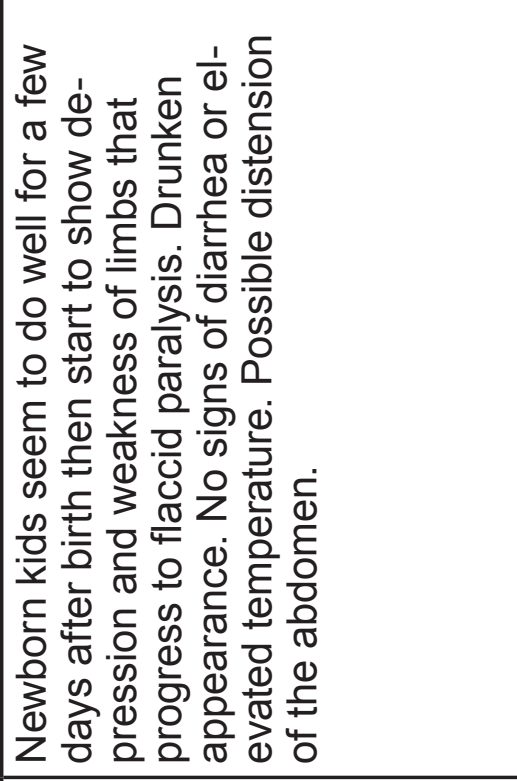 & & & \\
\hline 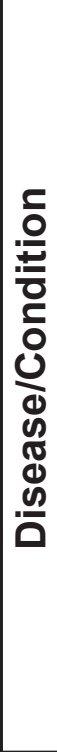 & 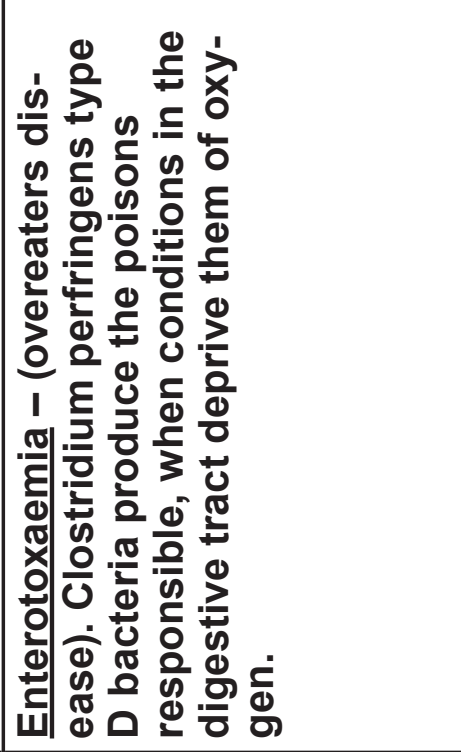 & 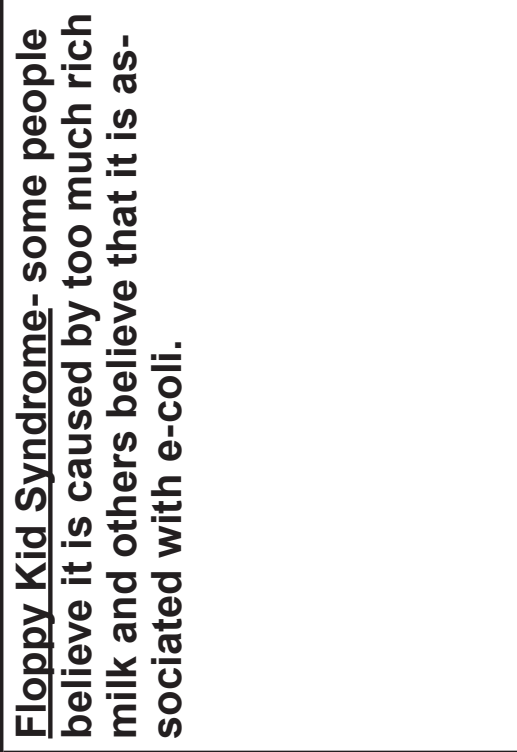 & & & \\
\hline
\end{tabular}




\begin{tabular}{|c|c|c|c|c|c|c|}
\hline 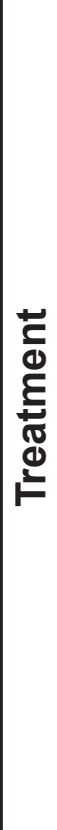 & 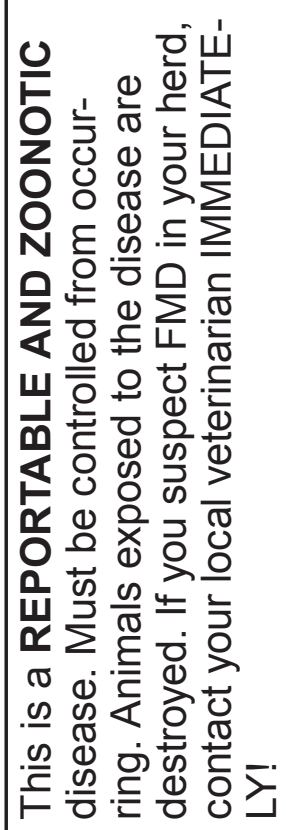 & 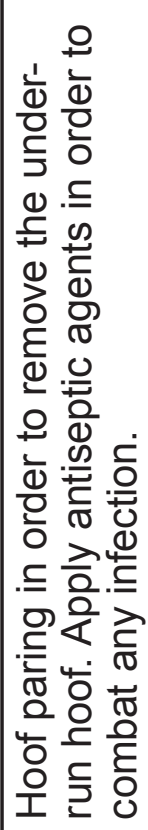 & 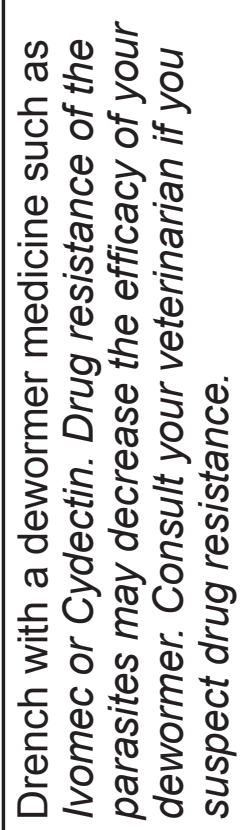 & & 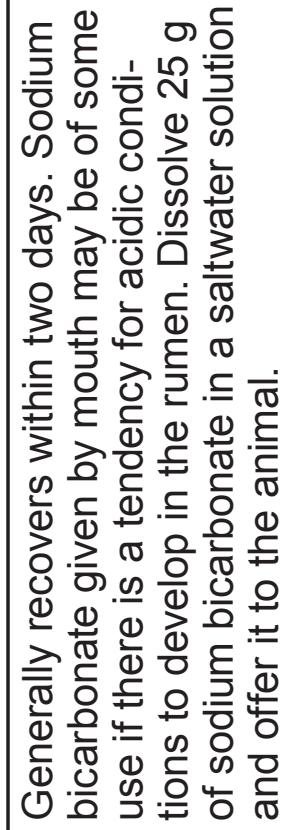 & 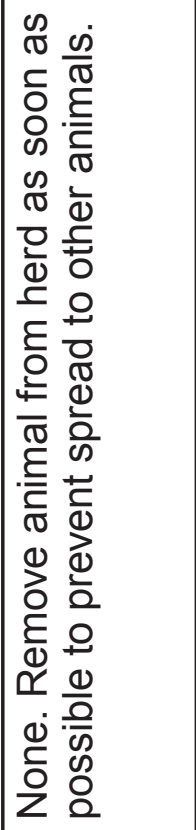 \\
\hline 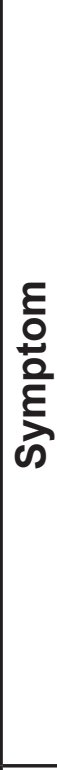 & 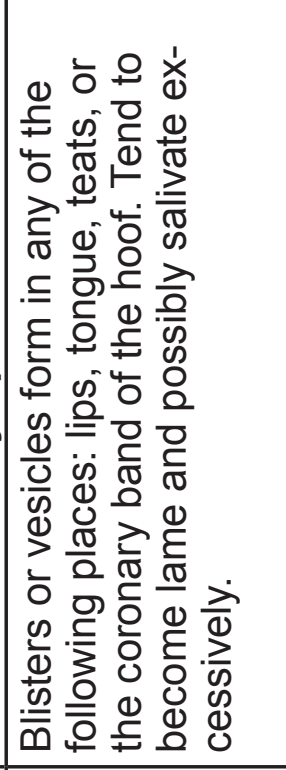 & 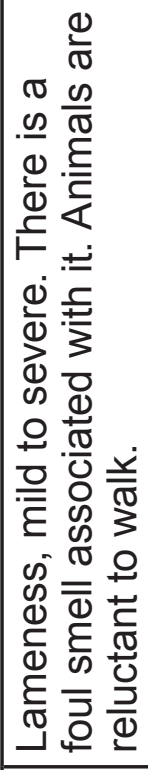 & 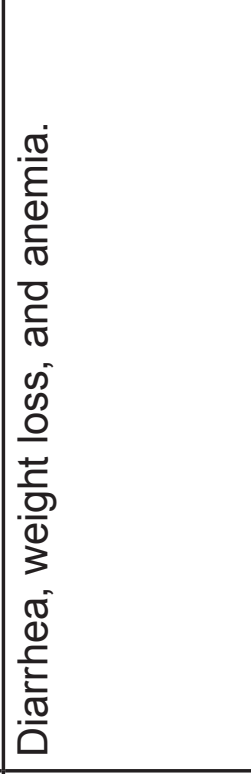 & & 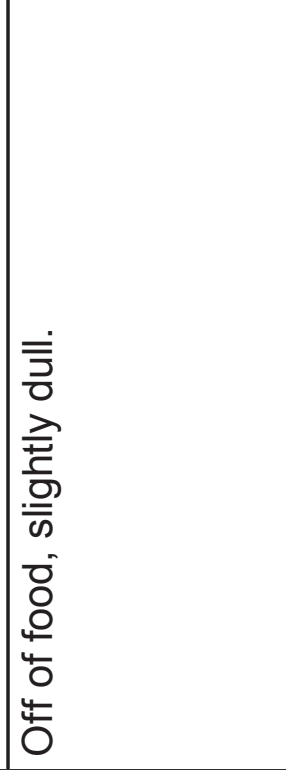 & 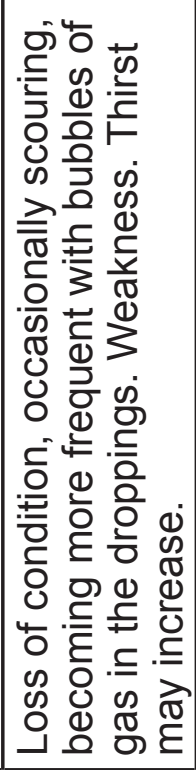 \\
\hline 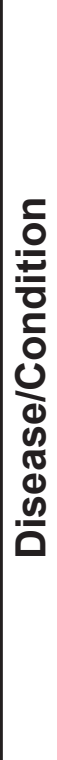 & 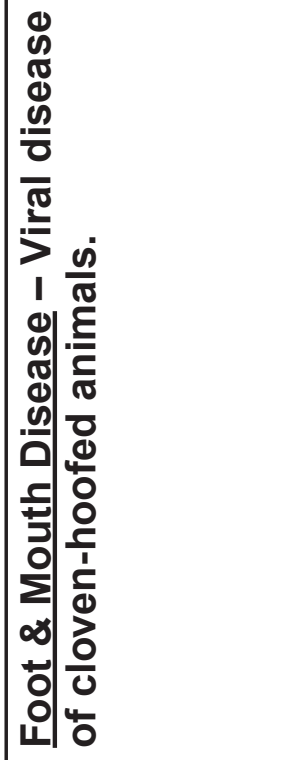 & 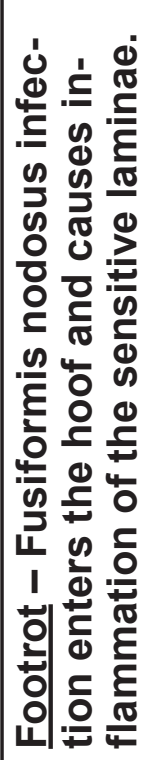 & 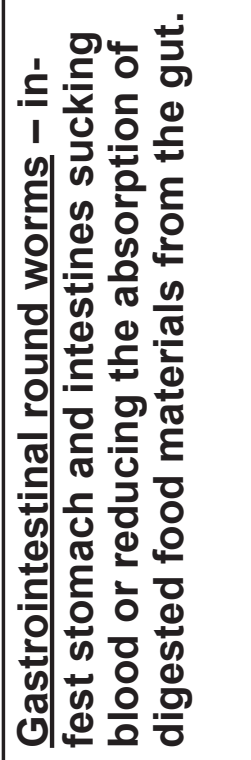 & 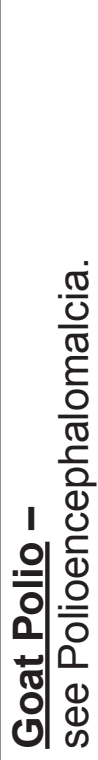 & 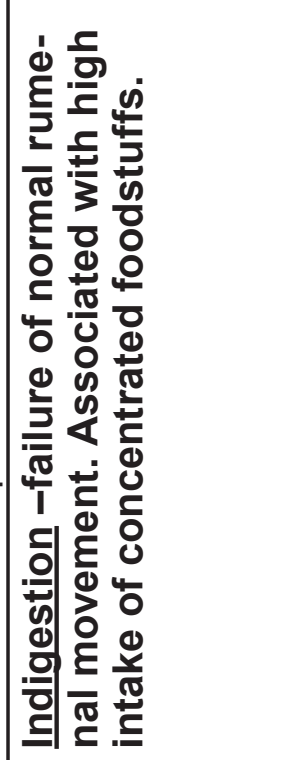 & 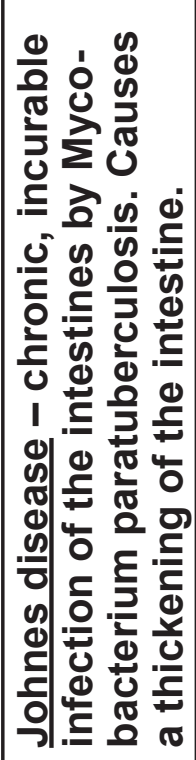 \\
\hline
\end{tabular}




\begin{tabular}{|c|c|c|c|c|c|}
\hline 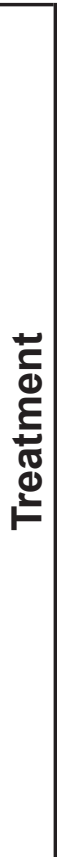 & 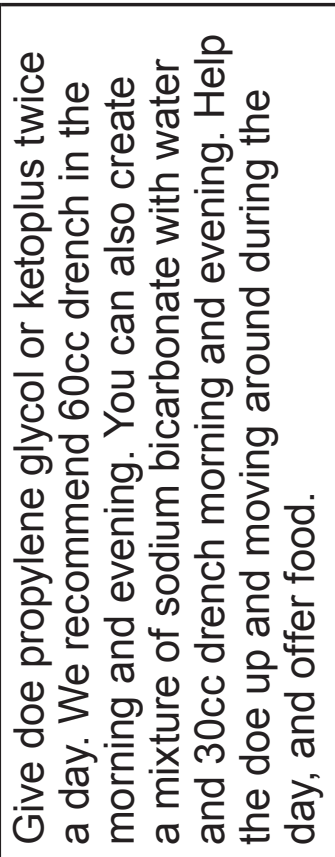 & 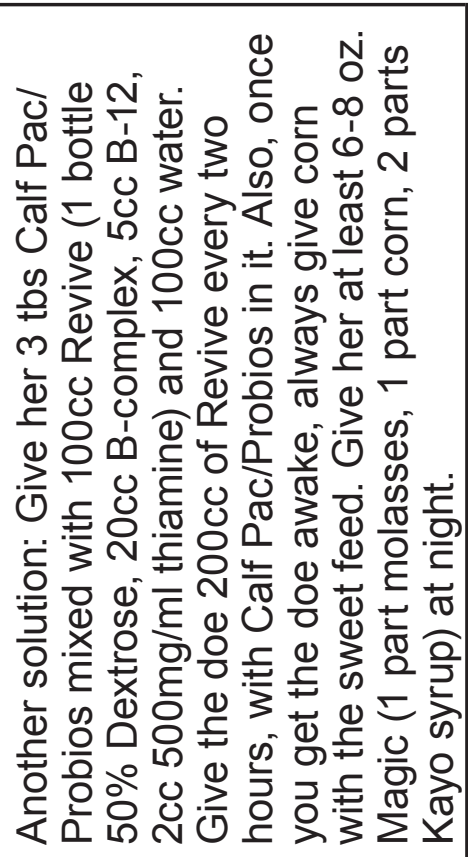 & 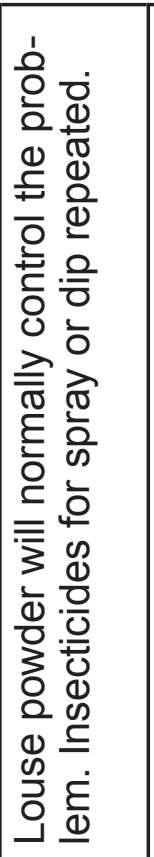 & 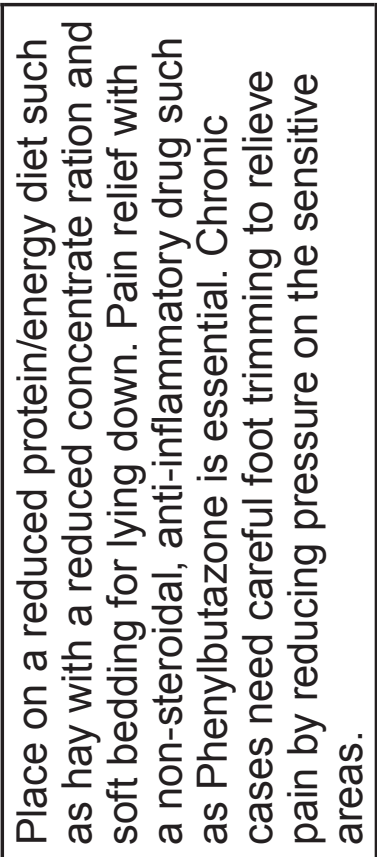 & 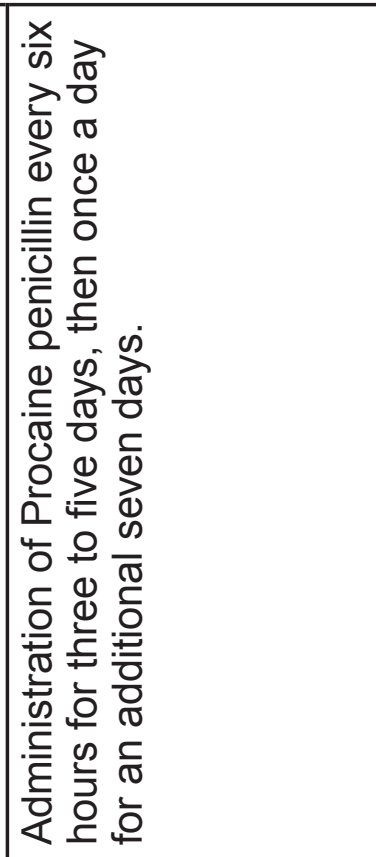 \\
\hline 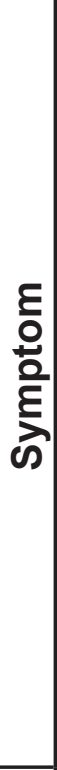 & 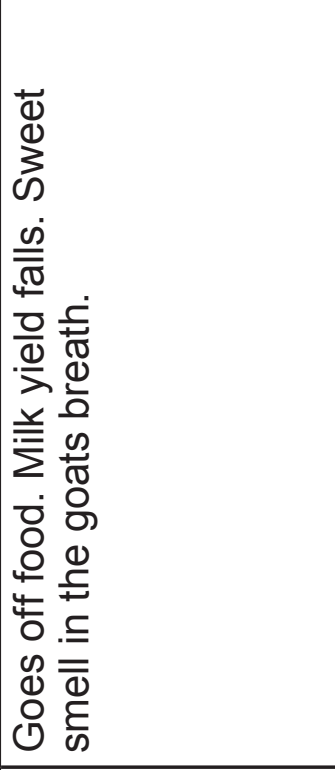 & & 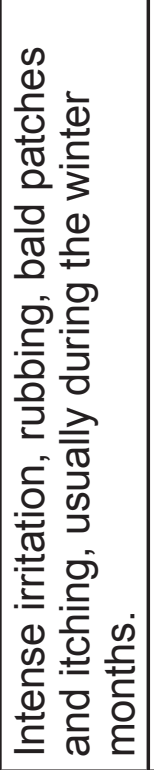 & 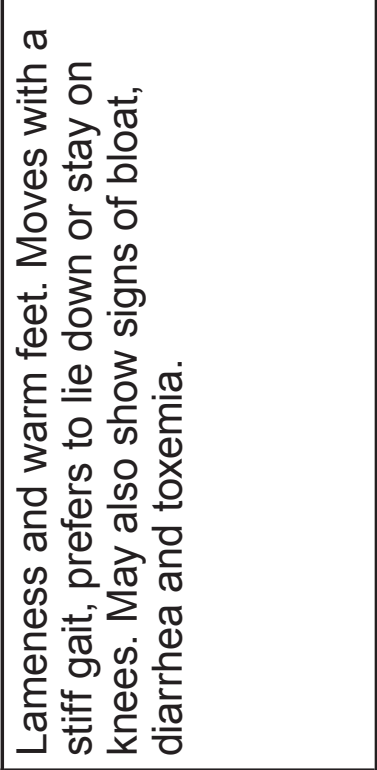 & 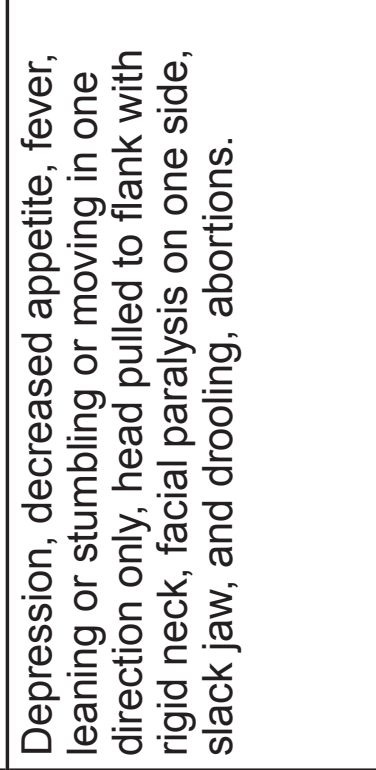 \\
\hline 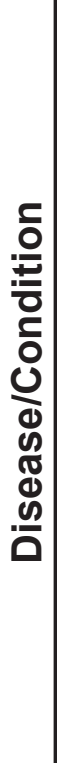 & 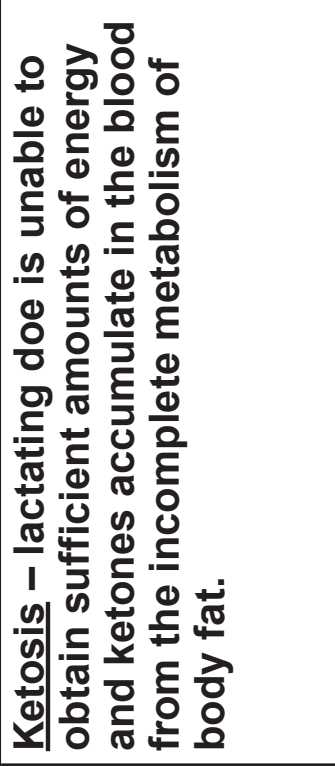 & & 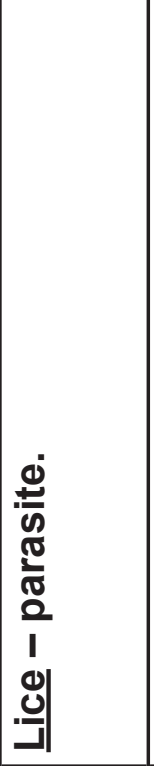 & 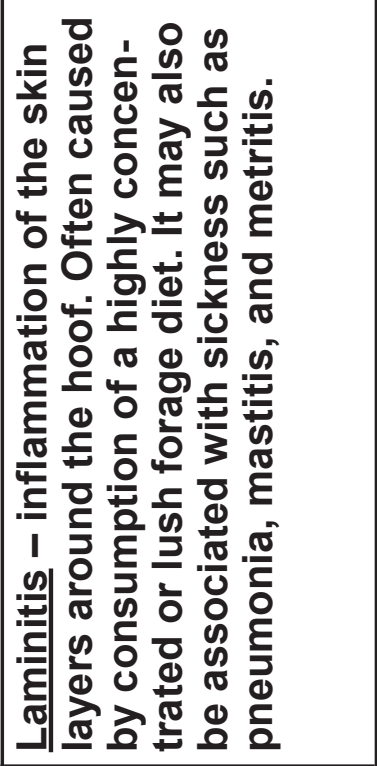 & 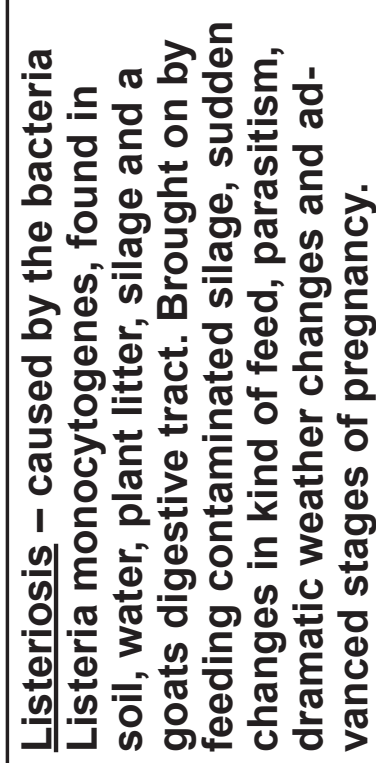 \\
\hline
\end{tabular}




\begin{tabular}{|c|c|c|c|c|c|c|c|c|c|}
\hline 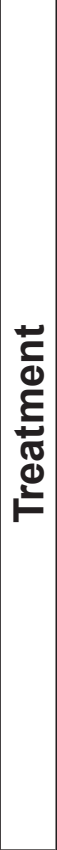 & 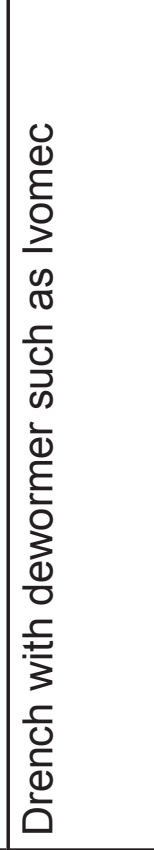 & 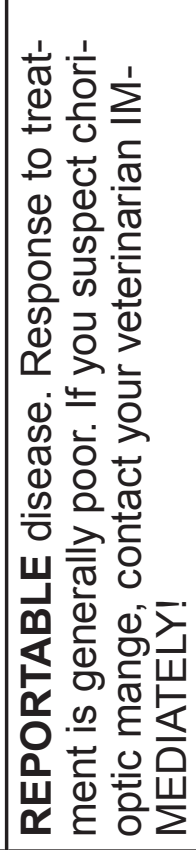 & 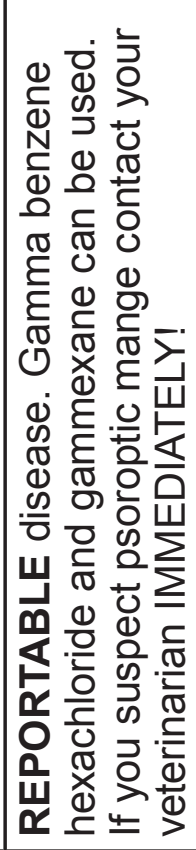 & 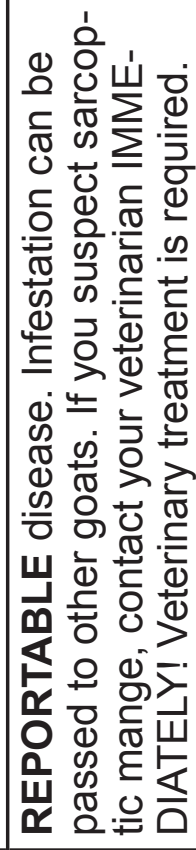 & 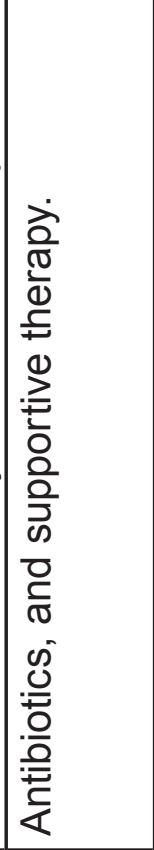 & 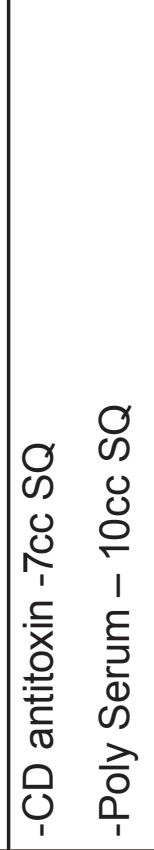 & 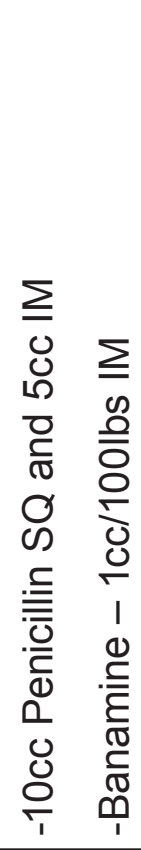 & 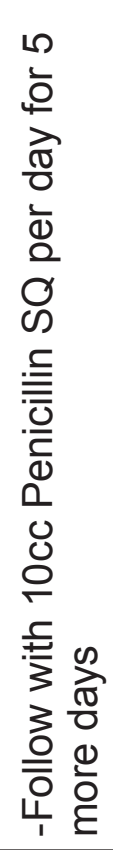 & 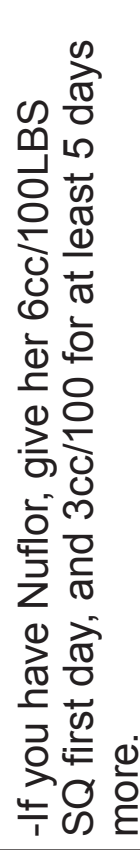 \\
\hline 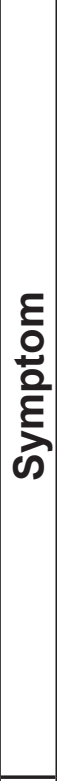 & 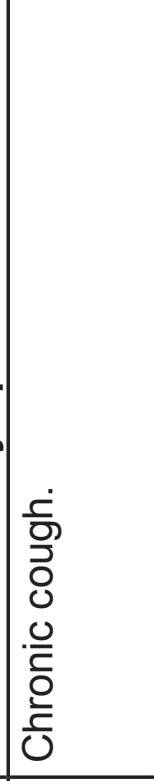 & 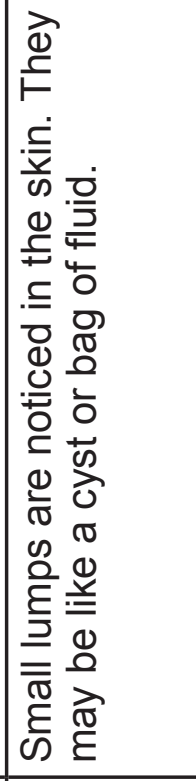 & 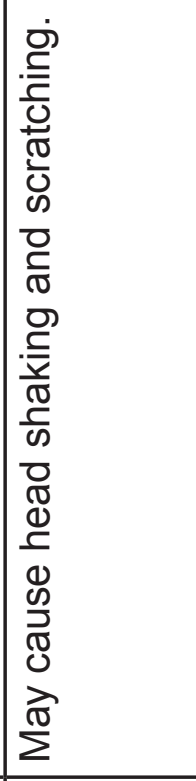 & 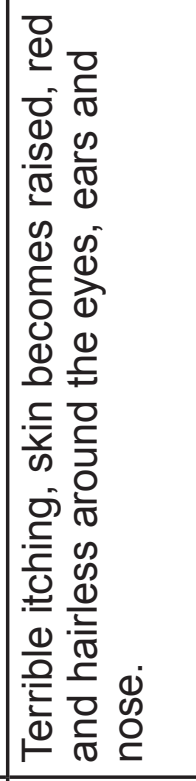 & 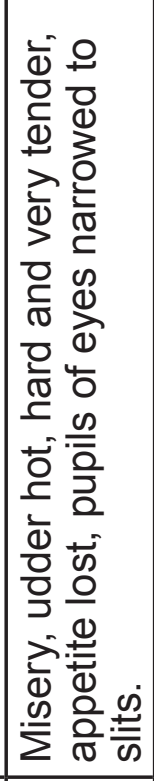 & 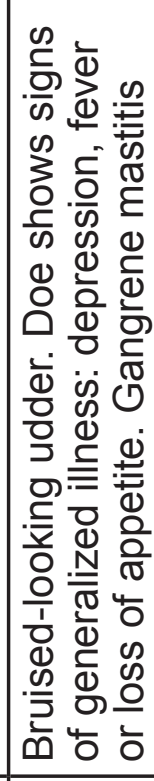 & 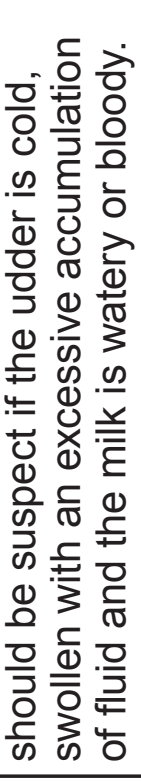 & & \\
\hline 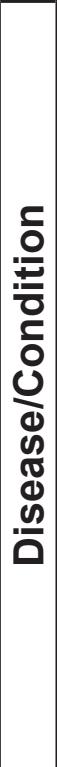 & 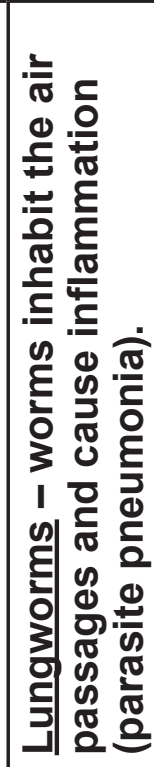 & 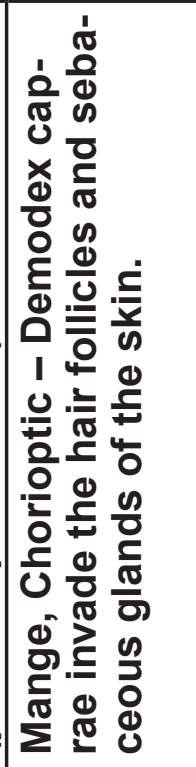 & 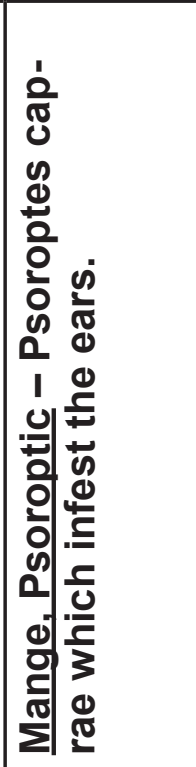 & 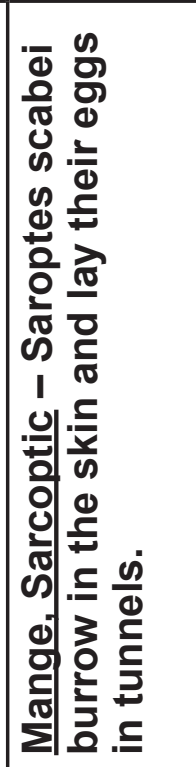 & 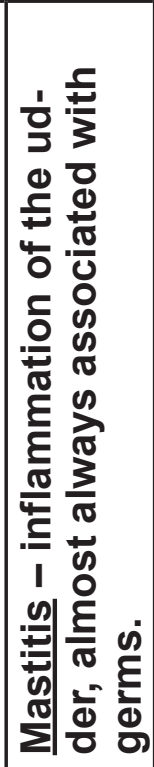 & 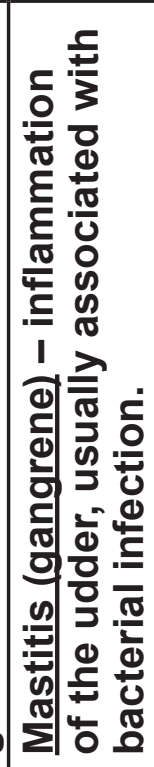 & & & \\
\hline
\end{tabular}




\begin{tabular}{|c|c|c|c|c|}
\hline & 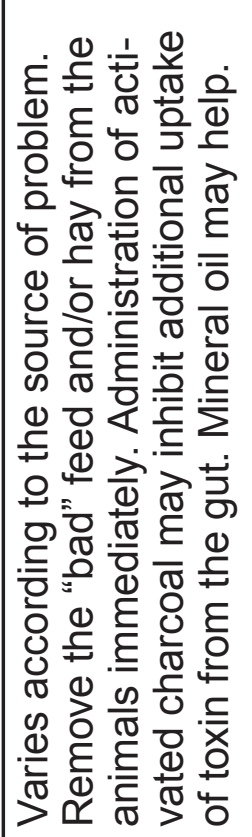 & 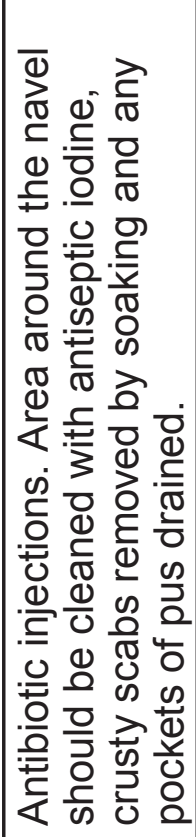 & 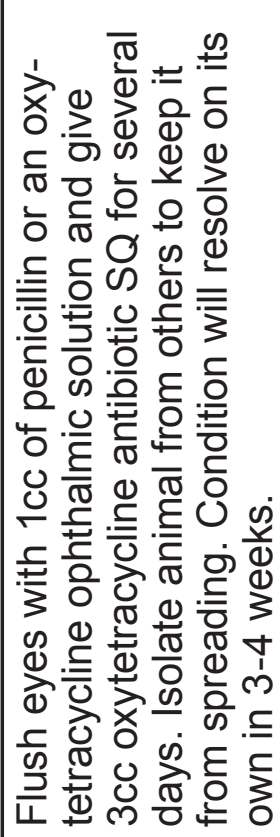 & 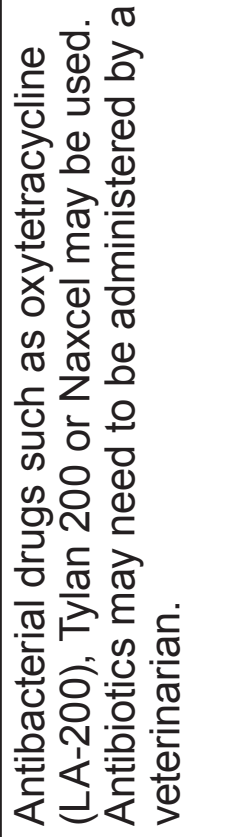 \\
\hline & 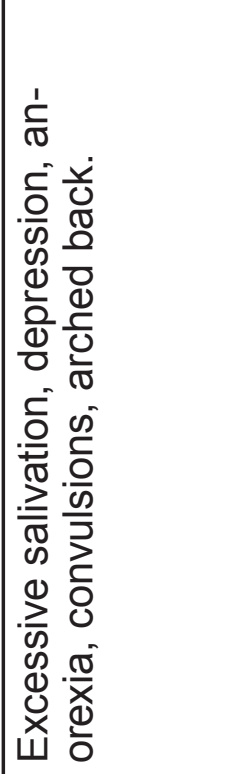 & 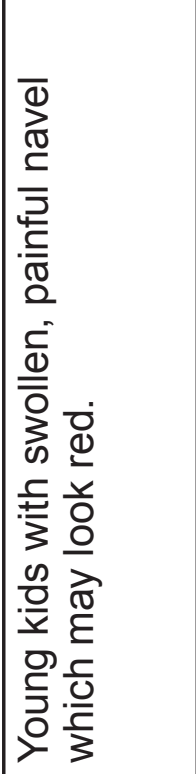 & 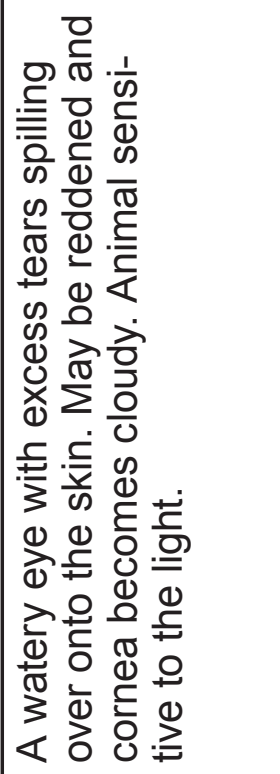 & 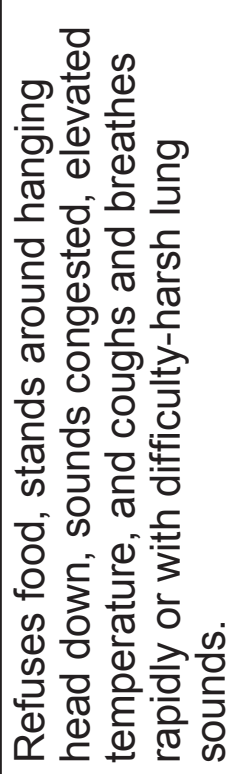 \\
\hline 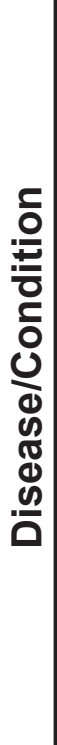 & 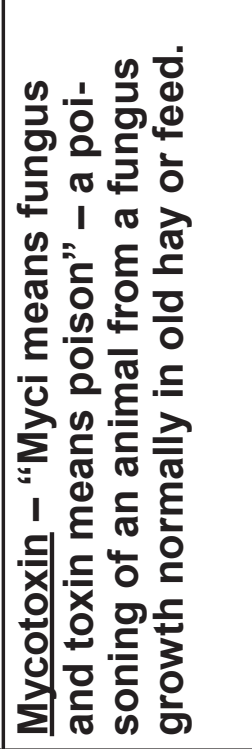 & 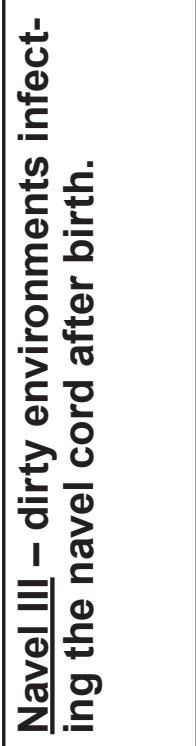 & 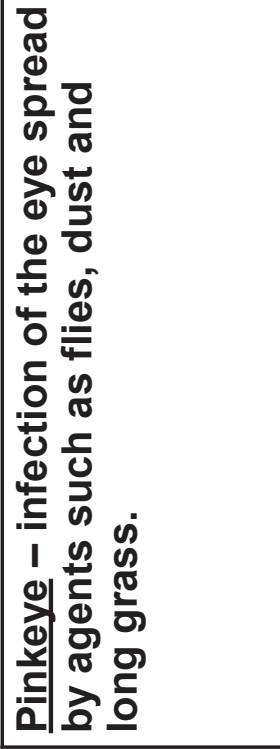 & 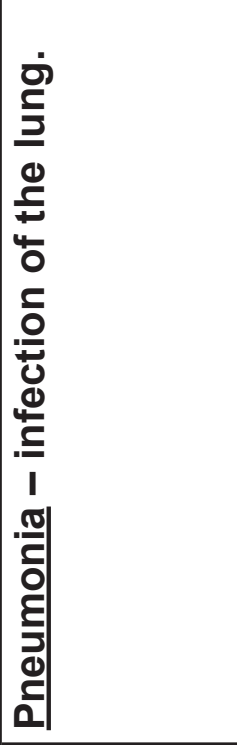 \\
\hline
\end{tabular}




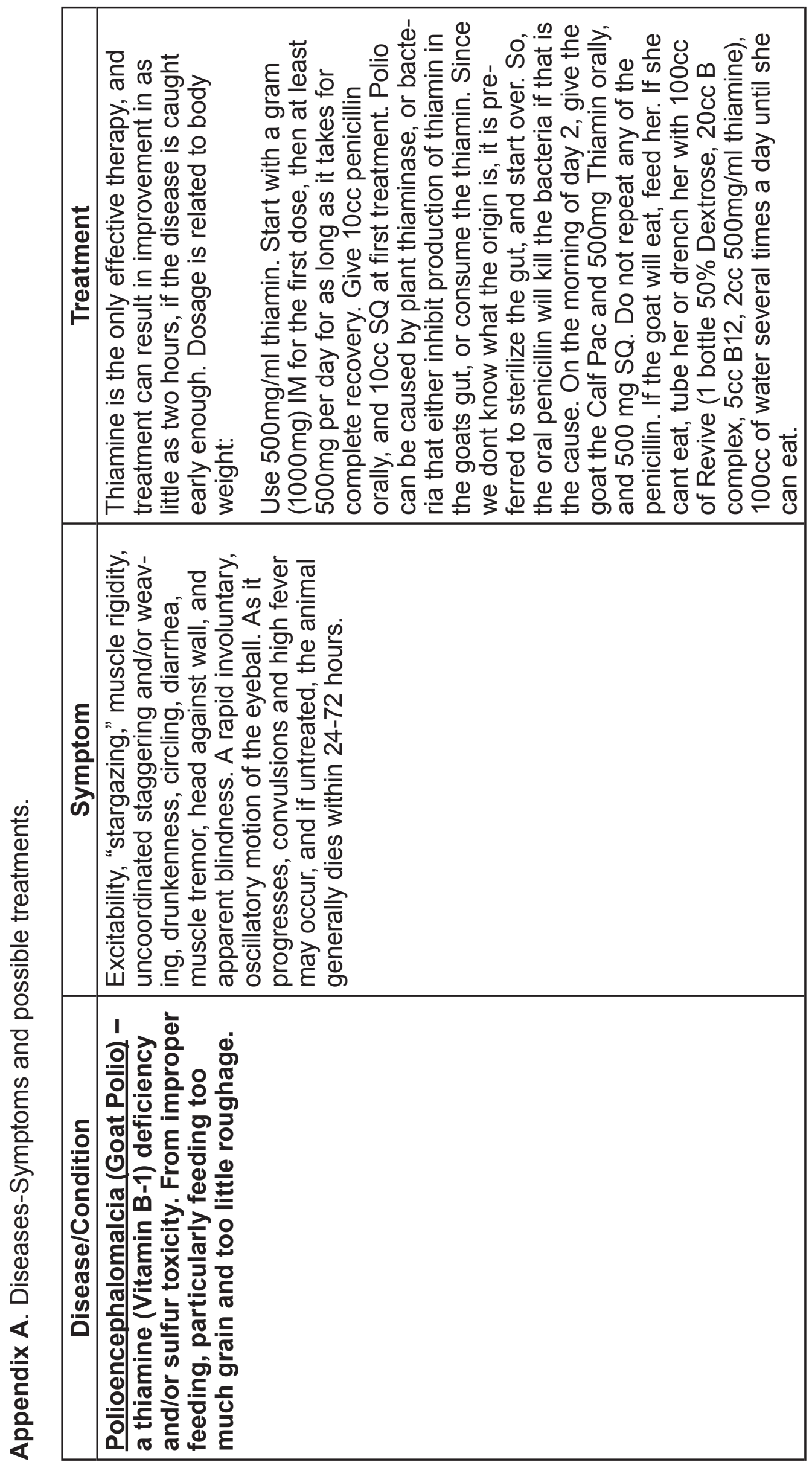




\begin{tabular}{|c|c|c|c|c|c|c|c|}
\hline & 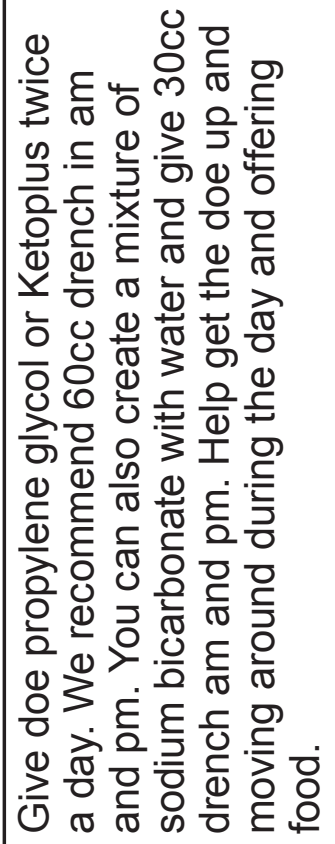 & 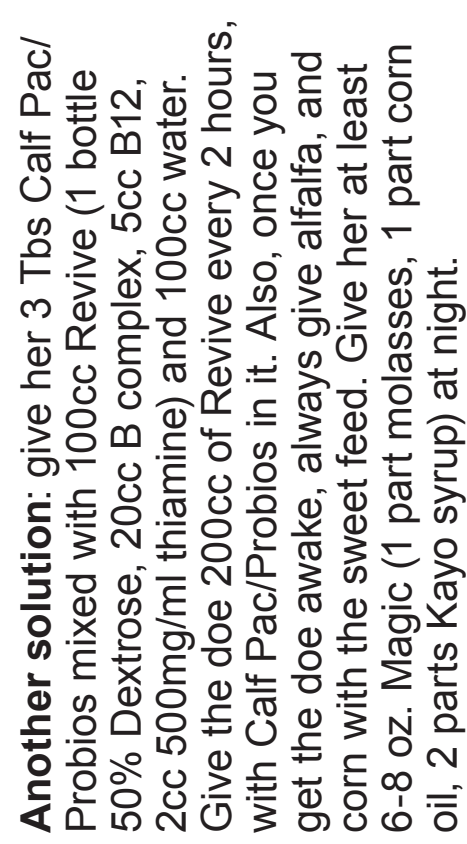 & 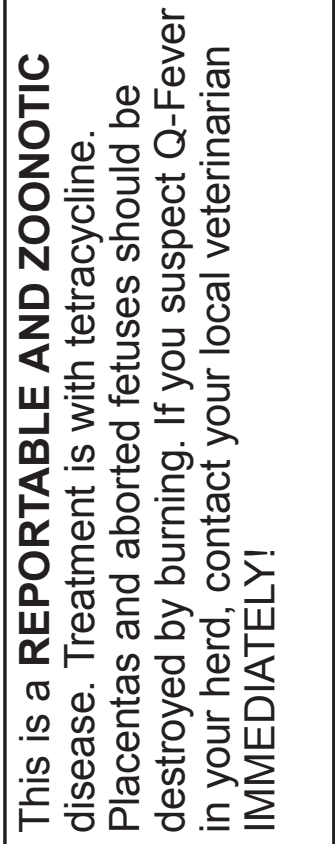 & 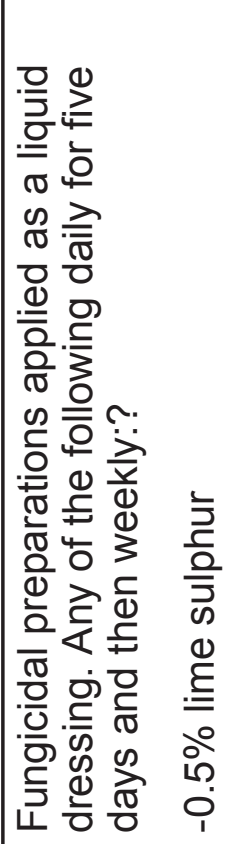 & 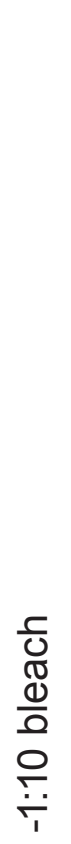 & 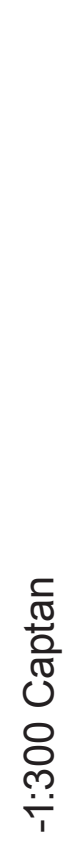 & 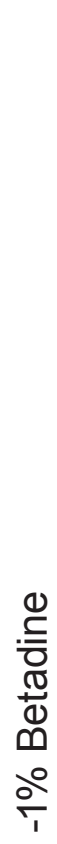 \\
\hline $\begin{array}{l}\frac{\varepsilon}{0} \\
\text { 을 } \\
\text { 을 }\end{array}$ & 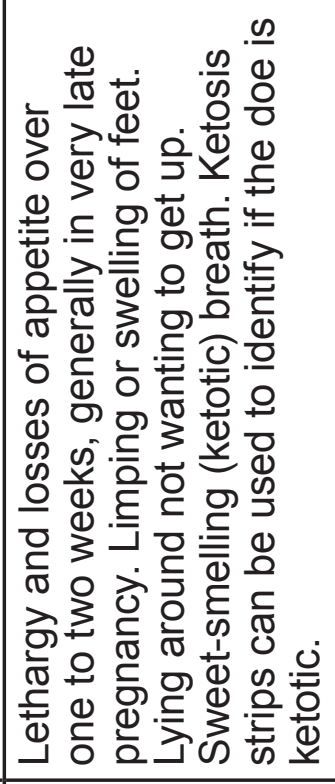 & & 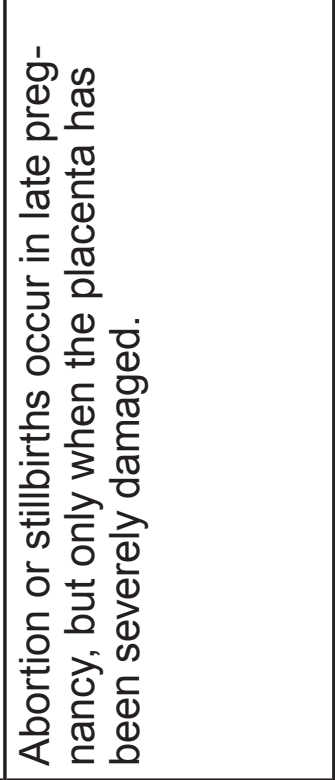 & 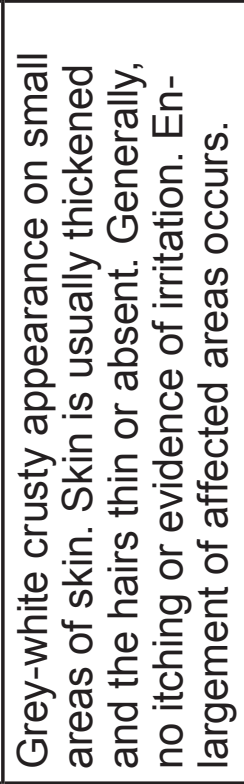 & & & \\
\hline 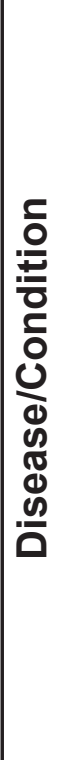 & 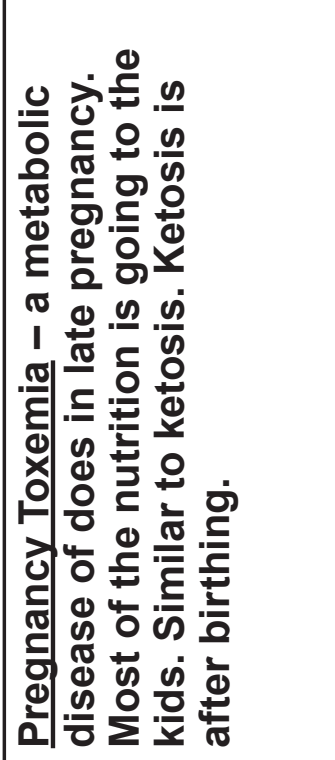 & & 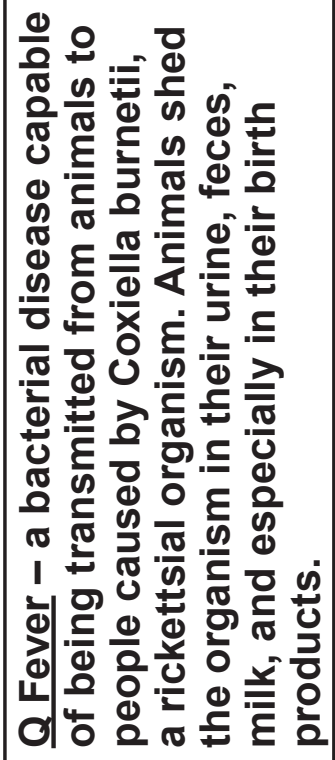 & 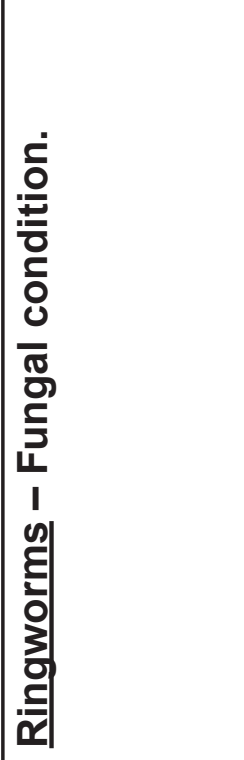 & & & \\
\hline
\end{tabular}




\begin{tabular}{|c|c|c|c|c|}
\hline & 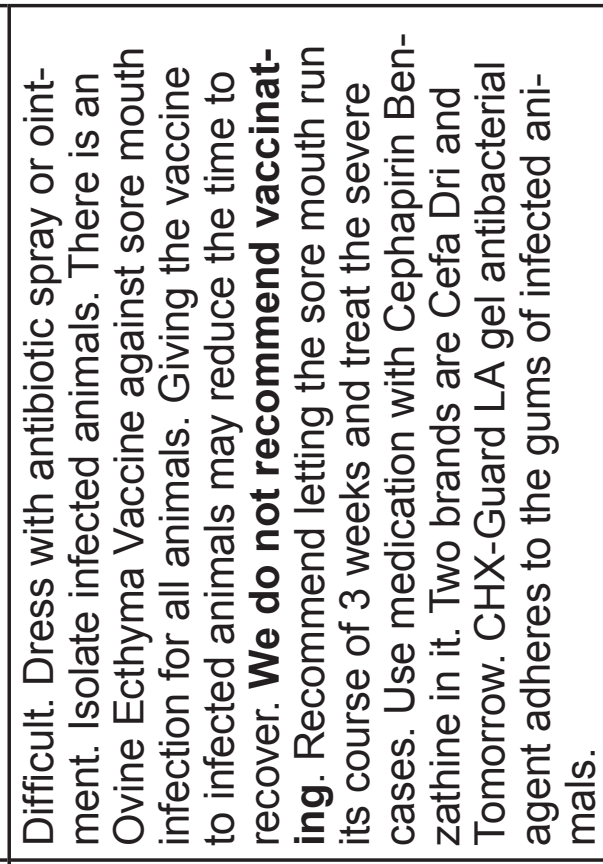 & 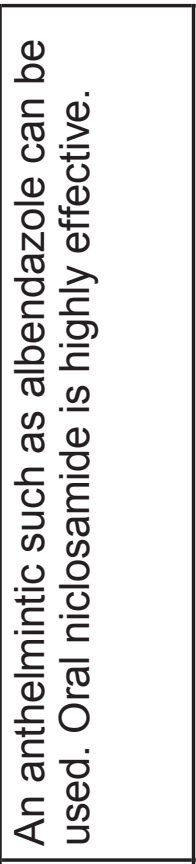 & 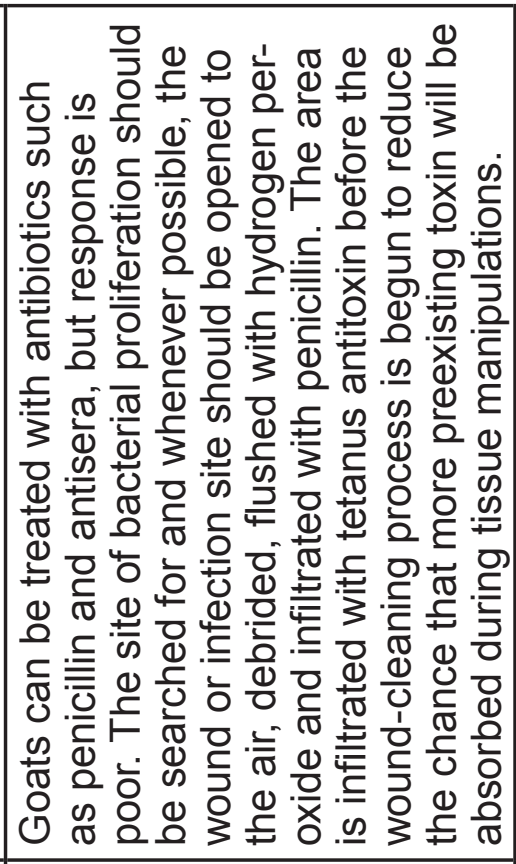 & 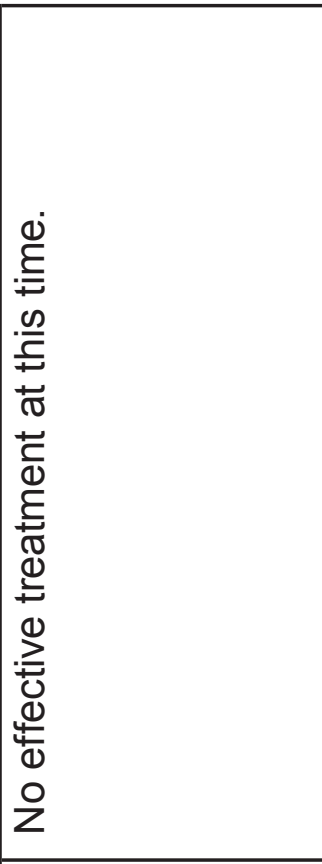 \\
\hline & 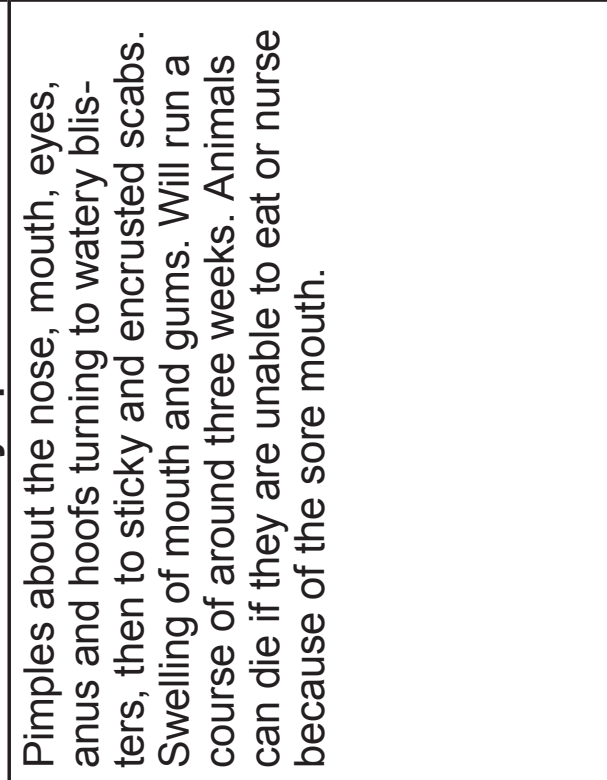 & 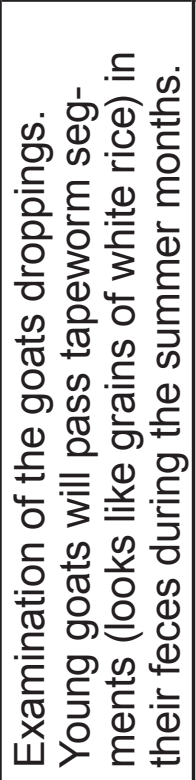 & 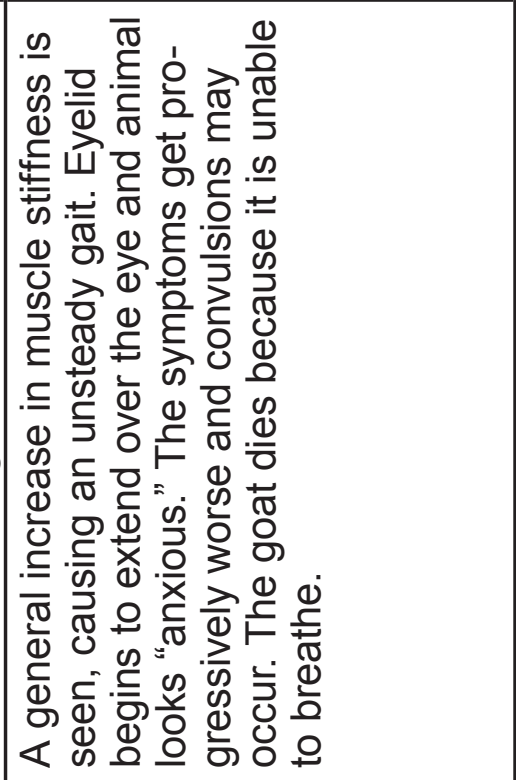 & 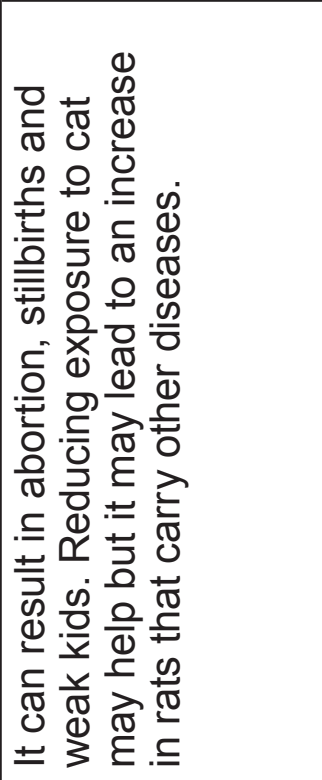 \\
\hline & 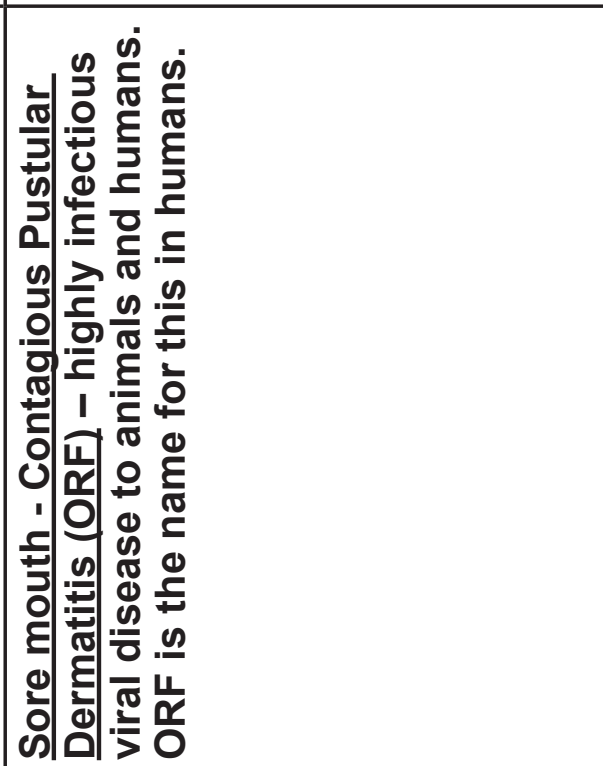 & 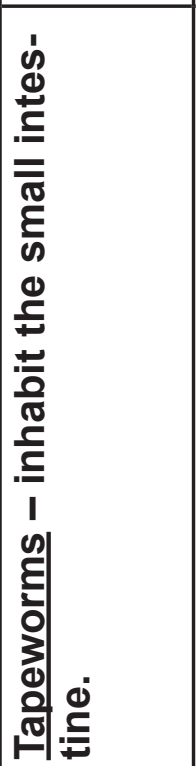 & 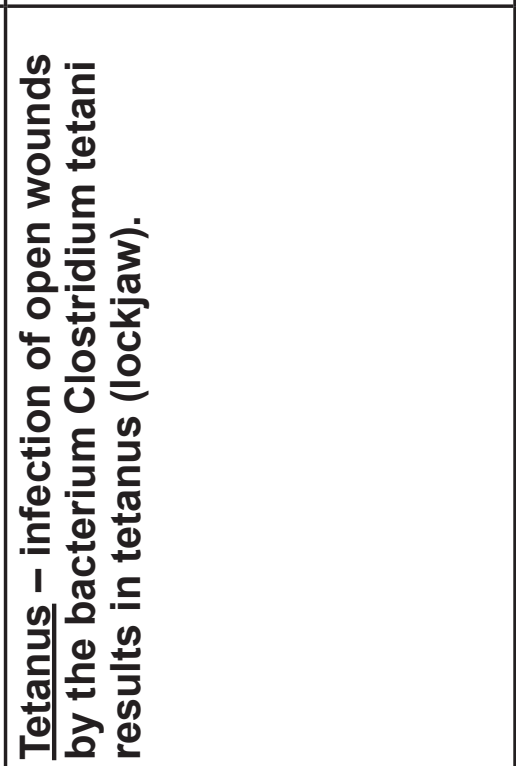 & 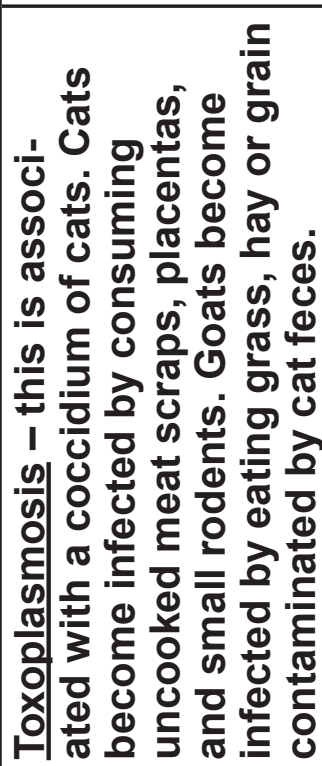 \\
\hline
\end{tabular}




\begin{tabular}{|c|c|c|c|c|}
\hline 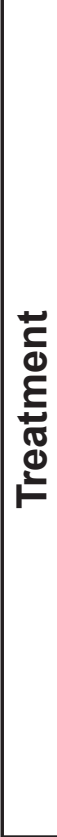 & 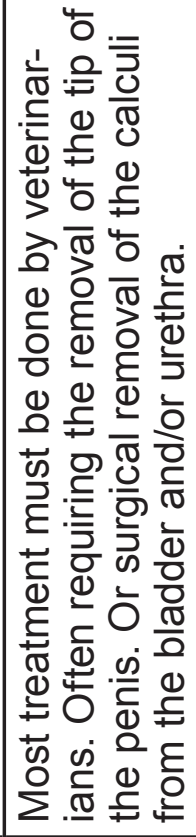 & 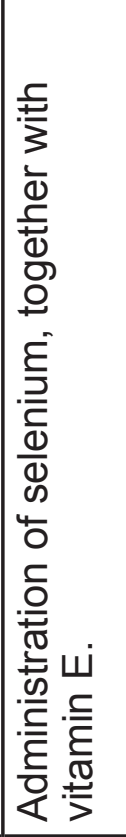 & 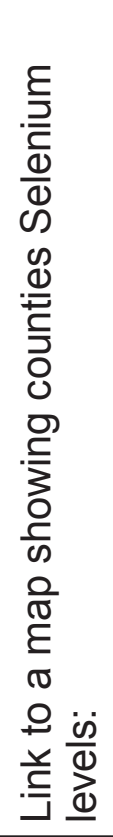 & 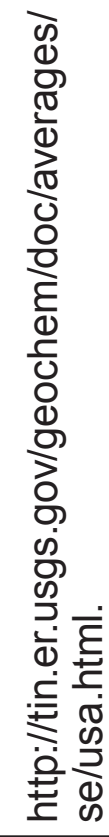 \\
\hline 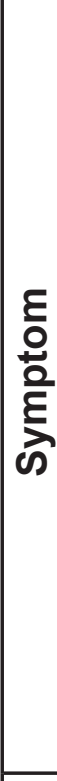 & 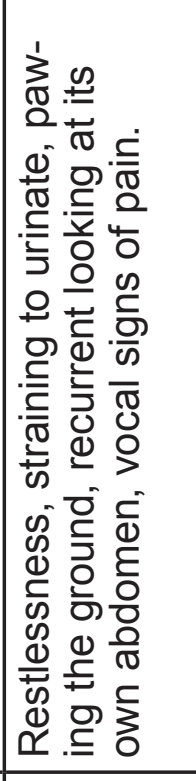 & 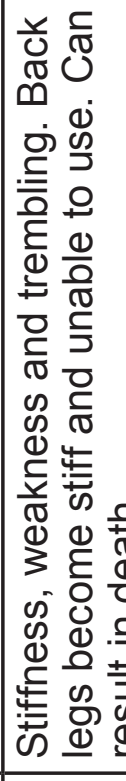 & & \\
\hline 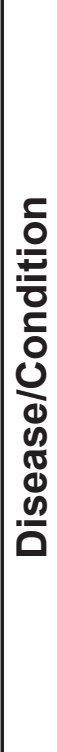 & 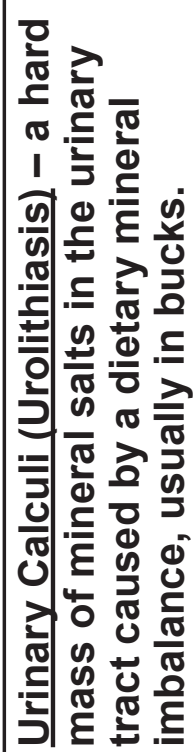 & 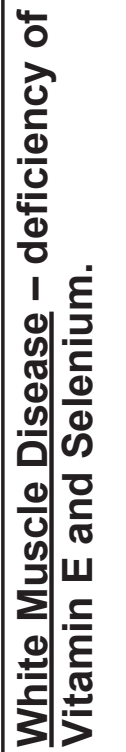 & & \\
\hline
\end{tabular}




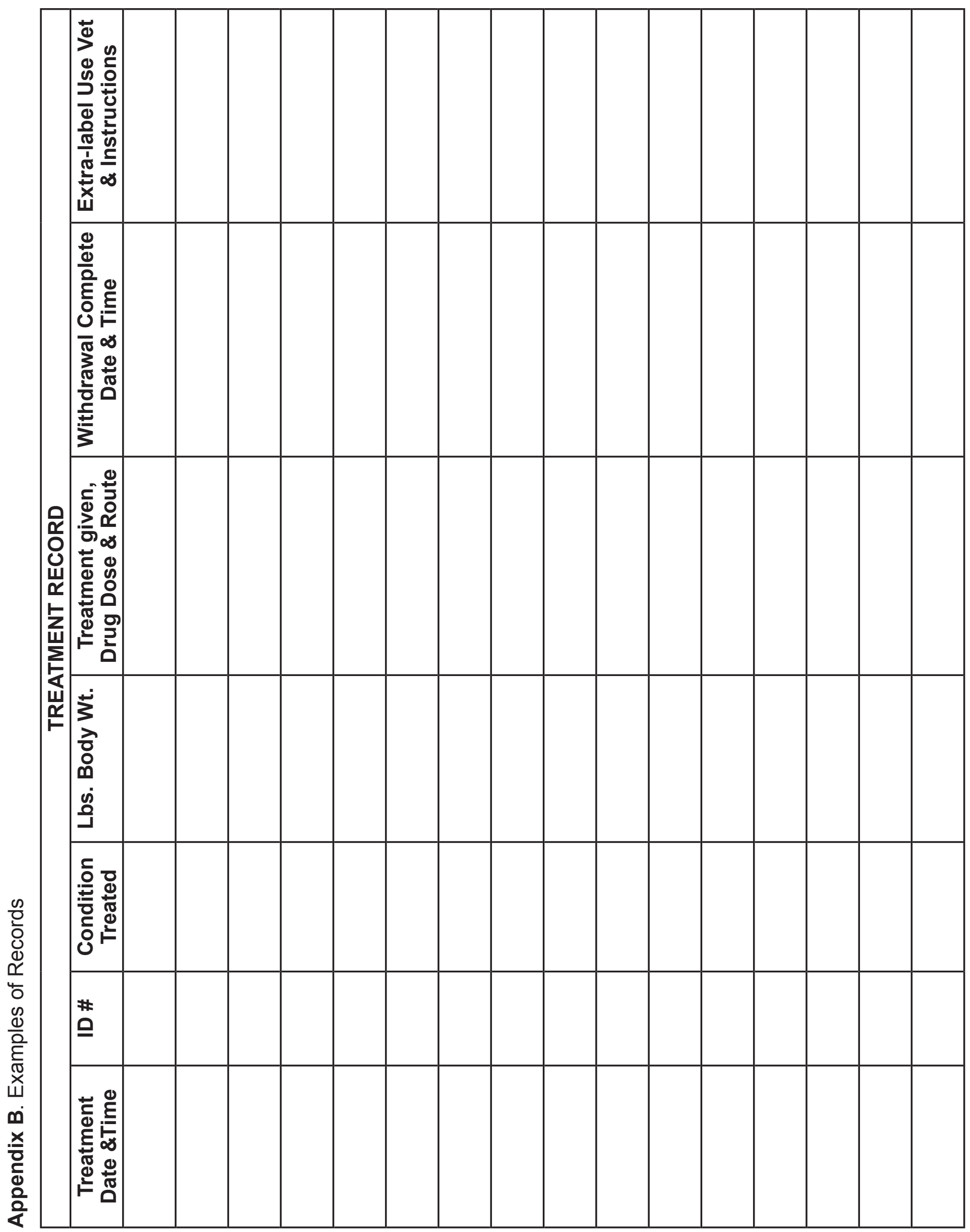




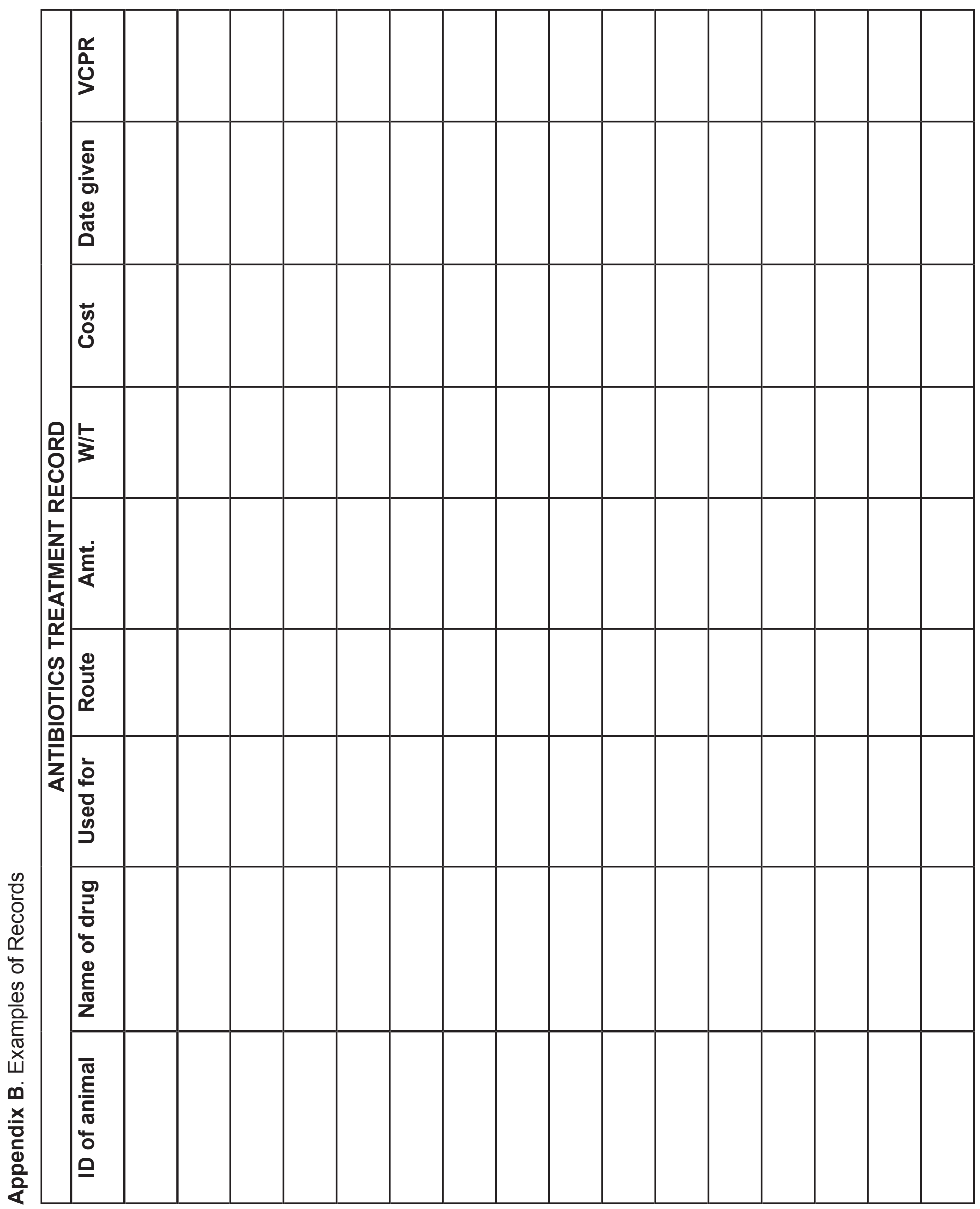


Archival copy: for current recommendations see http://edis.ifas.ufl.edu or your local extension office.

The Herd Health Handbook for Goat Producers: Control of Parasites in Goats

20

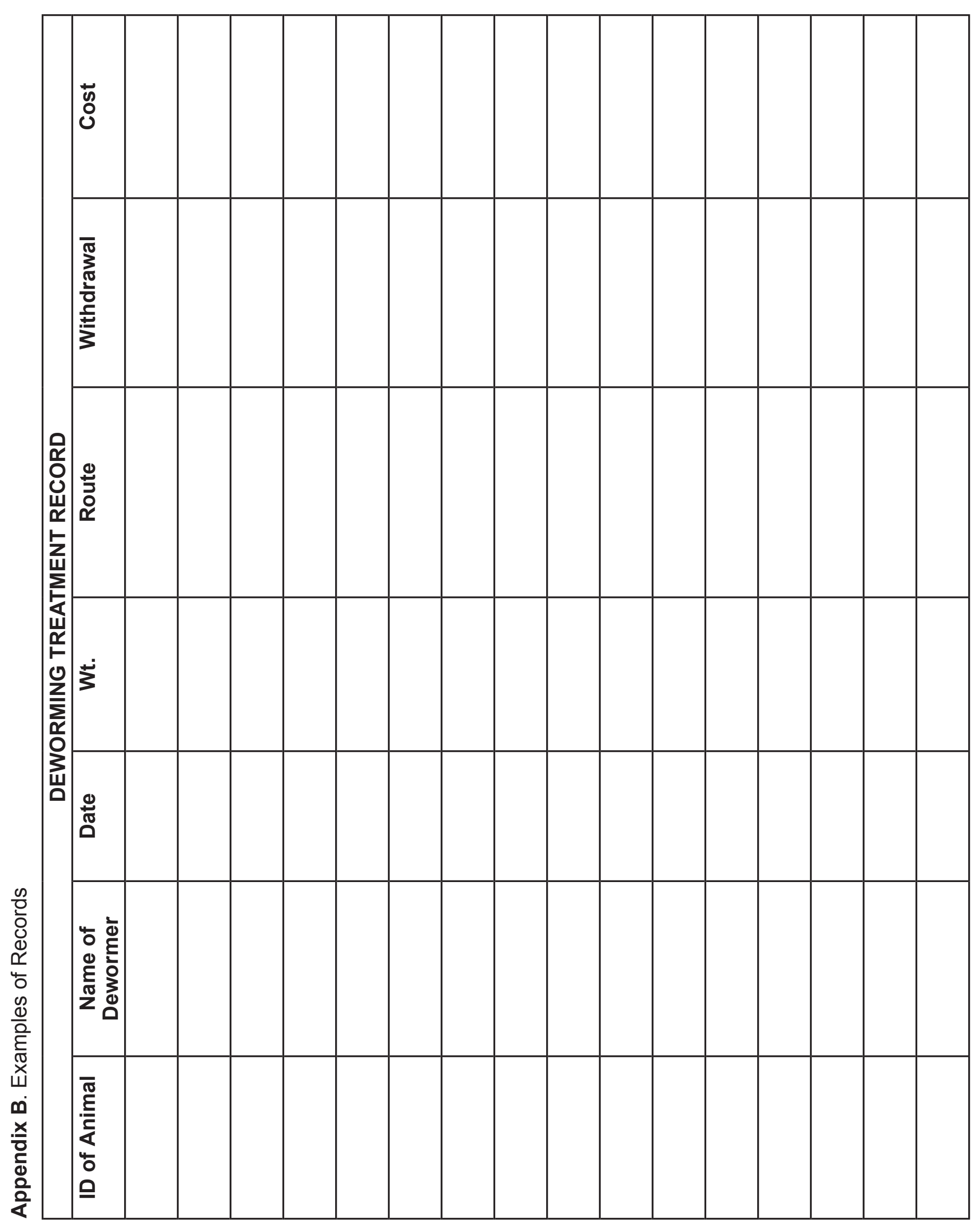

